\title{
Child care: Meeting the needs of working mothers and their children
}

Caroline Arnold

Jorge Mejia

Aster Haregot

Ann Leonard

Cassie Landers

Follow this and additional works at: https://knowledgecommons.popcouncil.org/departments_sbsr-pgy

Part of the Family, Life Course, and Society Commons, Gender and Sexuality Commons, International Public Health Commons, Maternal and Child Health Commons, and the Work, Economy and Organizations Commons

How does access to this work benefit you? Let us know!

\section{Recommended Citation}

Arnold, Caroline, Jorge Mejia, Aster Haregot, Ann Leonard, and Cassie Landers. 1991. "Child care: Meeting the needs of working mothers and their children," SEEDS no. 13. New York: Population Council. 

SEEDS is a pamphlet series developed to meet requests from all over the world for information about innovative and practical program ideas developed to address the economic roles and needs of low income women. The pamphlets are designed as a means to share information and spark new initiatives based on the positive experiences of projects that are working to help women generate livelihoods and to improve their economic status. The projects described in this and other issues of SEEDS have been selected because they have served not only to strengthen women's productive roles, but also to integrate women into various sectors of development, both social and economic. All projects documented in the SEEDS series involve women in decision-making, organize women locally, and address broader policy issues which affect the economic roles of women.

These reports are not meant to be prescriptive, since every development effort will face somewhat different problems and possibilities. Rather, they have been written to describe the history of an idea and its implementation in the hope that the lessons learned can be useful in a variety of settings. They are also being written to bring to the attention of those in decision-making positions the vital role that women play not only in the economies of their individual households but also in the economic life of every nation.

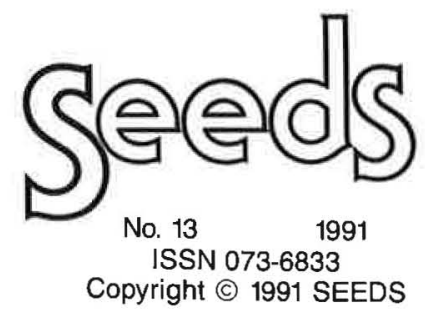

The Population Council provides project direction and administrative support for SEEDS. Editorial policy is set by the SEEDS Steering Committee: Judith Bruce (The Population Council), Marty Chen (Harvard Institute for International Development), Margaret Clark (The Aspen Institute), Anne Kubisch (The Ford Foundation), Ann Leonard (The Population Council), Cecilia Lotse (UNICEF), Katharine McKee (Center for Community Sell-Help), Anne Walker (International Women's Tribune Center), and Mildred Warner (Cornell University).

Publication of SEEDS is made possible by support of the Ford Foundation, The Government of the Netherlands, the Population Council and UNICEF.

Statements made and views expressed in this publication are solely the responsibility of the authors and not of any organization providing support for SEEDS. 


\title{
Child Care: Meeting the Needs of Working Mothers and Their Children
}

\author{
Edited by Ann Leonard \\ and Cassie Landers \\ Case Studies by: \\ Caroline Arnold: Nepal \\ Jorge Mejia: Ecuador \\ Aster Haregot: Ethiopia
}

\section{Introduction}

During the past decade, program initiatives in the areas of "women in development" and "early child development" have each received attention, but generally each subject area has its own proponents and practitioners as well as its own agenda for action. Rarely is it acknowledged that the major constituency for all of these efforts is one and the same: women with young (infant and preschool) children. Today most women within both the developing and developed worids must work to insure the survival, let alone the well-being of their families. One of the most gnawing questions all working mothers face is, who will care for the children? And beyond the issue of who will provide care for children is the question of the quality of care the children will receive, an issue that affects their health, their socialization skills and their intellectual development.

In this edition of SEEDS (developed in cooperation with the Consultative Group on Early Childhood Care and Development, with support from UNICEF), we seek to bring together the critical elements of women's work and child care, reviewing the issues from three different perspectives: child care as a means of enabling women to work, as a source of employment for women, and as a way of meeting the developmental needs of young children. We will examine three different UNICEF-supported approaches to child care on three different continents--Asia (Nepal), Africa (Ethiopia) and Latin America (Ecuador) - that have been developed with the needs of working women in mind and, in two instances, alongside program components that support women's economic activities. These examples not only offer positive solutions for women who work, but also provide opportunities for many women to receive training and to develop management and leadership skills, as well as gaining employment as child care providers. 


\section{Women's Work and Child Care}

They already grow most of the developing world's food, market most of its crops, fetch most of its water, collect most of its fuel, feed most of its animals, weed most of its fields.

And when their work outside the home is done, they light the third world's fires, cook its meals, clean its compounds, wash its cloths, shop for its needs, and look after its old and its ill.

And they bear and care for its children. ${ }^{1}$

The vast majority of mothers in the world today are working and earning. Where they work may range from the family compound, to neaby fields, to local markets, to industrial parks to corporate headquarters, but in both developing and developed countries women are economically active, providing support for themselves, their children and their families. In 1985, the official rate of female labor force participation was 32 percent. In India, for example, women were contributing, exclusive of services as housewives, 36 percent of the nation's net domestic product. In fact, since 1950 the growth of women's participation has surpassed that of men by two to one.?

In the Third World, while women have always carried a heavy burden of work in suport of the family, the effects of industrialization, urbanization, migration and the severe global economic recession of the 1980s have forced more and more women to seek paid employment, generally in addition to their unpaid but vital household production responsibilities. An even greater number of women, however, earn income in the informal sector where work is typically low paying and insecure. ${ }^{3}$ In addition, the same factors noted above, combined with changing social patterns, have resulted in many more women becoming the primary source of economic support for their families: In Ghana it is reported that over 29 percent of households are headed by women, ${ }^{4}$ and in some societies the number can reach as high as 50 percent of all households with children. As Marianne Schmink notes in her introduction to a report on Women, Low-income Households and Urban Services in Latin America, "many women in working-class households are in sole support or important contributors to household income," and "for mothers, access to some form of day care is probably the single most important factor determining participation in income-earning activities."

\section{Working Mothers}

Not only are more mothers working but, in both the modern and traditional sectors, more mothers with very young children now find it nec- essary to venture further from home in order to provide a livelihood for the family. While it is difficult to find statistical breakdowns of the number of working mothers in most parts of the world, especially where large numbers of women are employed in the informal sector, in the United States today nearly 57 percent of women with children under the age of six are employed and the trend appears to be growing. ${ }^{6}$ The number of women returning to the job market in the U.S., within one year of giving birth, for instance, rose from 31 percent in 1976 to 50.8 percent in 1987.7 Results of the Infant Feeding Study show that in Bangkok, Thailand approximately one third of mothers surveyed were working within the first year following child birth; 20 percent employed away from home by the time the child was two months old and 31 percent by the time the child reached 12 months. In Nairobi, Kenya, 25 percent of mothers surveyed were working by the time their child reached six months and 29 percent were employed when the child was nine to ten months of age. ${ }^{8}$

For all of these working mothers, the critical question is who is going to care for their children while they are working because, in virtually all parts of the world, providing suitable child care arrangements is the responsibility of the woman. As Dwyer and Bruce point out, "becoming a parent has a significant effect on women's time use and very little on men's." Balancing the need to work against the safety and welfare of her children is an ever-increasing source of anxiety for working women; one that is alleviated only when adequate child care is available.

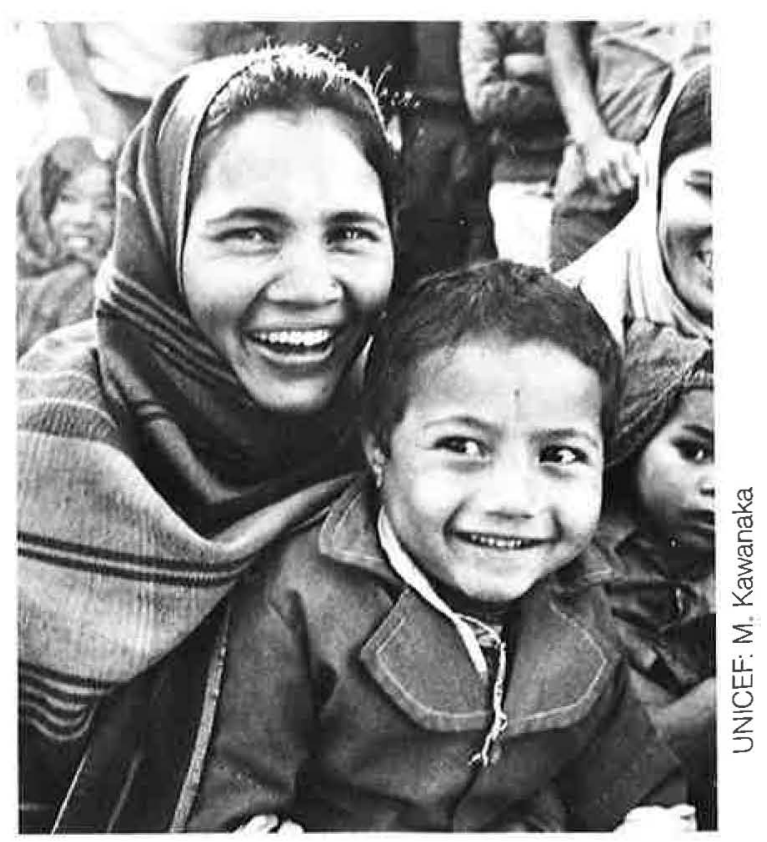




\section{Availability of Child Care}

When adequate child care is available.... The problem is that in too many cases it is not available, and when suitable arrangements do not exist, women face not only limitation of employment options and confinement to low-income occupations (where there is generally greater flexibility), but frequent high levels of stress, anxiety and fear. In a study of the need for and availability of child care in Mexico City, Kathryn Tolbert found that the economic crisis of 1982 had forced many married women back into the job market. Most were coping with their child care needs by taking children with them to work, leaving children with relatives, neighbors or older siblings and, for short periods of time, leaving them alone (sometimes tied to their beds to keep them safe). ${ }^{10}$

Economic necessity, migration and changing social patterns are also making extended families a much less reliable source of child care. As Tolbert discovered in Mexico City, "Grandmothers, important in myth and reality in the third world for caring for children, are present in only 15 percent of the homes, while other extended family or other members are present in 10.8 percent of homes." 11 Research has shown that reliance on family and neighbor networks in urban settings is often a reciprocal arrangement which does not allow for full-time or regularly scheduled employment.

Another serious deficiency of the extended family model is where older siblings-usually girls - are removed from school to care for younger children. Not only may the care they provide be of dubious quality, but the girls themselves are being deprived of educational opportunities.

Obviously there is a need for another care giving alternative: delegation of responsibility to a formally or informally organized system of child care. Such programs come in forms ranging from highly organized preschool facilities to informal home day care arrangements where care givers look after a group of neighborhood children. Child care programs also may be located within cooperatives and factories, or provided by communities, with varying degrees of participation by and cost to working mothers.

While recent initiatives in child care have increased the number of children enrolled, unfortunately there are not nearly enough of them. In addition, many of these new programs have been almost totally child development oriented and have not been designed with any thought of meeting the needs of working mothers. Hundreds of small-scale demonstration projects, as well as several large-scale initiatives in early child education designed to foster children's abilities, are in operation. For example, through an Integrated Child

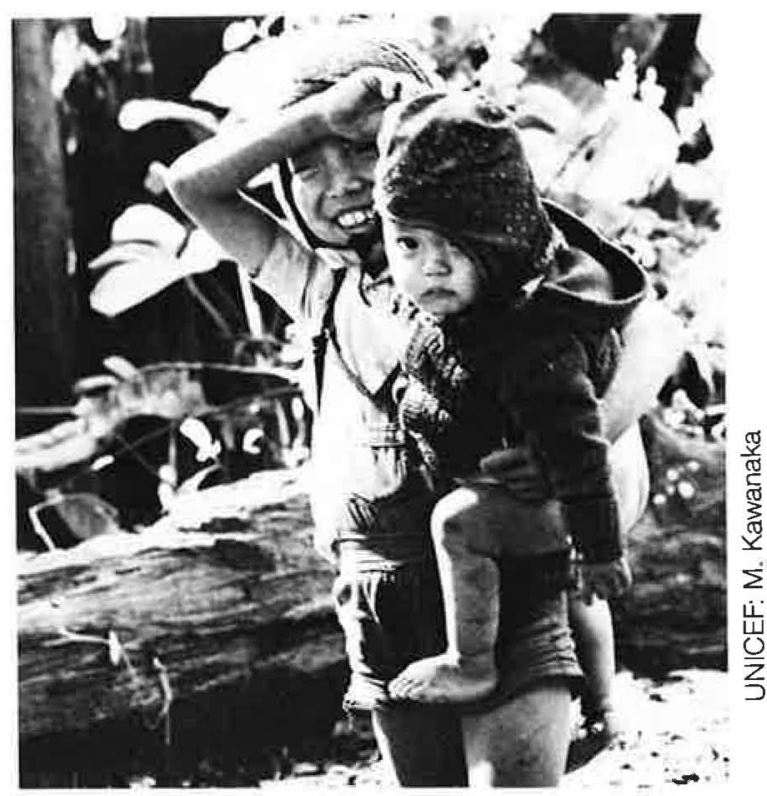

Development Services project, India now provides non-formal preschool programs for more than 25 percent of all children between the age of three to six and is expanding its reach to include the needs of very young children, as well as pregnant and lactating mothers. In Peru, more than one-fourth of all children between the age of three to five are targeted for preschool and integrated child development programs, while in Sri Lanka, this expansion is seen in efforts to cover all five year old children by extending the age of entry into primary school downward and transforming the first year of schooling into a kindergarten. ${ }^{12}$

However, the reach of such programs is generally limited due to inadequate human and financial resources and/or lack of government commitment. In addition, many of these programs have serious drawbacks for working mothers: care is often offered only for children age three and above and, typically, programs operate for three to four hours a day and only during the week. And when care for infants is available, there often is no provision for mothers to continue breastfeeding. The failure of such programs to consider the logistical and economic constraints faced by working mothers drastically reduces the number of children they can benefit. Another problem of many comprehensive child development programs is that while their overall goal is to address the health, nutrition and development needs of young children, in reality many are able to provide only minimal, "custodial," care.

Yet, some child care programs tailored specifically to meet the needs of working women do exist and some effective strategies have been identified. In addition to those cited in this edition of SEEDS, India's "mobile creches" are day care 
facilities located at construction sites that provide services to women construction workers with small children. In rural areas, some agricultural cooperatives have developed systems of day care where women take care of children on a rotational basis during peak planting and harvesting seasons.

The classic factory day care facility, fostered by the International Labour Organization in the early decades of this century, still offers worksite care for young children of factory workers in some locations. However, the success of such initiatives has been limited at best given that employers often choose to replace women workers with men rather than assume the costs of day care. Also, women workers frequently are unwilling to submit their children to the hardships and indignities of traveling with them on overcrowded public transportation to and from work sites every day. Taking children far from home, even for good quality day care, raises many concerns for low-income mothers. As Anderson and Panzio found in Lima, Peru, "The lack of guarantees of a minimal level of safety was evident as well in the women's fears about sending small children away from home for whatever purpose." Women are relucant to take children on city buses not only because accidents are common, but because "women traveling with sacks of merchandise, their market baskets, and small children are powerless to defend themselves" both against thieves and sexual harrassment. ${ }^{13}$

Transportation is, in fact, a critical issue for many working mothers because not only do they work long hours and for meager pay, but they often live far from work sites. Most of the urban poor are congregated in marginal settlements located on the periphery of large cities. Transportation may take "one fifth to almost one third of a minimum daily wage and may take between three to five hours a day." This means that "work days for women who must travel from one part of the city to another are often as long as 13 or 14 hours when transportation time is included." 14 For rural women, the distance between the village and her fields may be great and she must also put in long hours traveling, usually by foot, to seek water, fuel and fodder.

Programs that offer child care for a limited time each day may address health and nutritional needs and provide educational stimulation for children, but they offer little beyond added frustration for most working mothers. In the case studies that follow, we see how the problem of working women and child care is being addressed through direct participation of local communities in three different regions of the world. In two of the cases, Nepal and Ecuador, new "home care" approaches for addressing child care needs are operating along side more traditional, centerbased approaches. It is clear that the home care approaches, and the community supported and operated model in Ethiopia, are more successfully meeting women's needs not only by providing quality care during realistic working hours, but by helping to empower women to better help themselves, their children and their community. As Tolbert notes about similar approaches in Mexico, they "are the seeds of social change for women through a process of dignifying their need or desire to work, legitimizing the community's concern for its children, and by bringing together women with similar needs to form, often for the first time in their adult lives, meaningful associations with a group of women from outside their family."15

\section{Child Care Providers}

In addition to offering convenient, quality, affordable child care to women who work, these cases demonstrate that community-based child care can also provide employment opportunities for local women. Working as a child care provider is not only a source of remuneration for many lowincome women, but an opportunity to receive training, develop management skills and increase their status within the community. On the other hand, once trained, child care providers may still earn less than other comparably skilled workers: When working women as a whole continue to earn on average two-thirds of the income earned by working men, it is not surprising that the wages paid to those entrusted with the care of their children are at the bottom of the salary scale. For example, in Ecuador trained preschool teachers earn approximately 40 percent of the salary of primary school teachers and, in the U.S., a 1989 survey revealed that child care providers were earning on average 30 percent of the salary paid to the average elementary school teacher. ${ }^{16}$ The result can be frequent turnover of day care personnel as the newly "trained" providers move on to more lucrative employment.

Whether or not women with children, particularly young children, should work may still be a fashionable topic of debate but the fact is that they do work and must earn in even greater numbers. What is needed now is to recognize this reality and develop more and better options for providing child care solutions suitable for working mothers while at the same time providing children with a safe and supportive environment that meets their developmental needs. It is hoped that the following examples offer some indication of what is possible as well as pointing to what still remains to be done. 


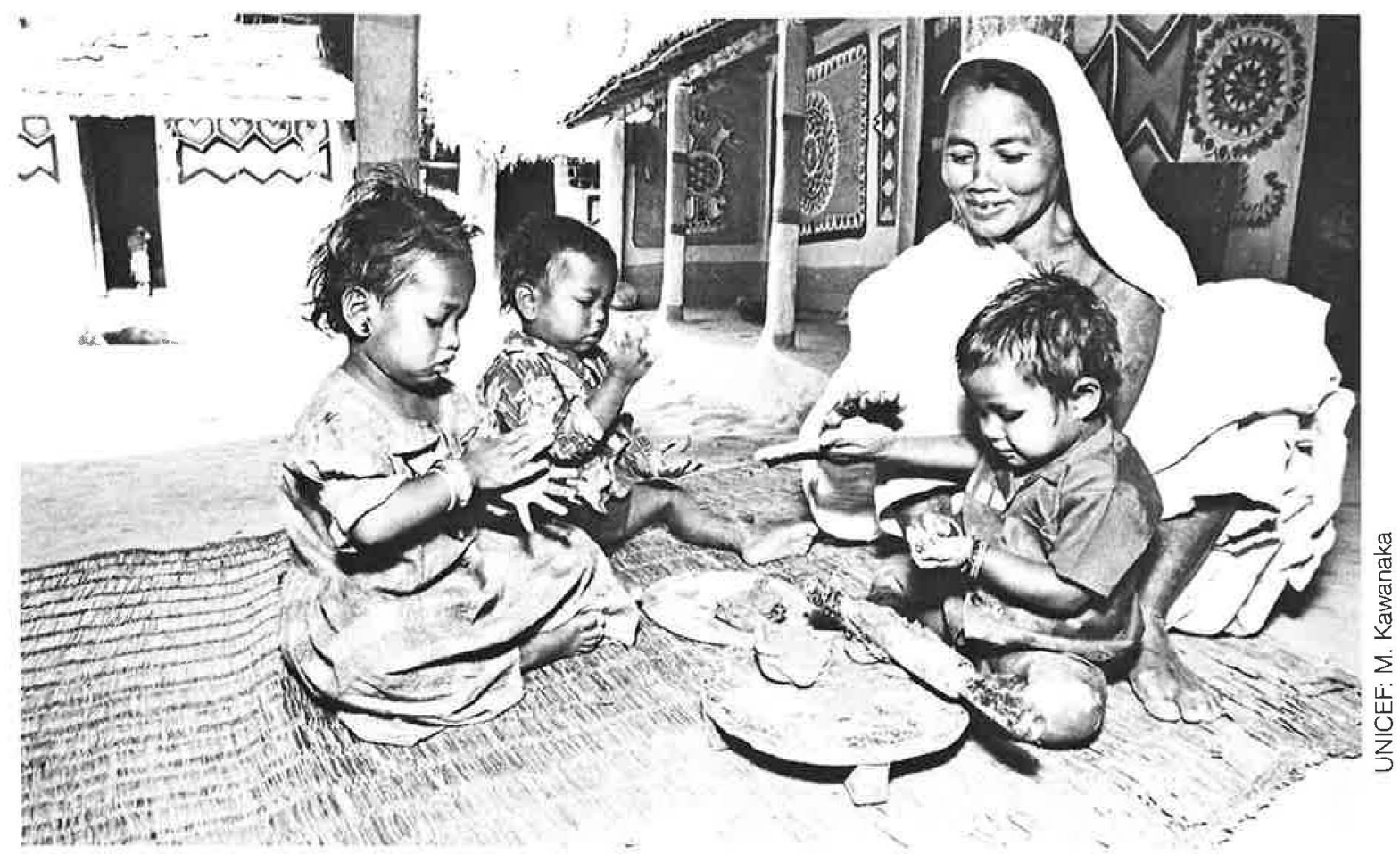

Nepal: Project Entry Point

\section{Background}

Nepal is a country of great diversity. Wedged between India and China, the land descends from the world-famous peaks of the Himalayas, through the hills, to the flat sub-tropical plains known as the terai. Ninety-four percent of Nepal's population live in rural areas; around half in villages inaccessible by road. The country's great variety of terrain is matched by its great diversity of ethnic groups and cultural practices.

The population of Nepal is close to 18 million, including eight million children under the age of fifteen. Large families, averaging six children or more, are the norm. The significance and resilience of the family constitutes a point of convergence across the different ethnic groups. However, in all cases, pressure is now being felt by these large extended families as land holdings, which have been divided and redivided for generations, become too small to support so many people.

Population and ecological pressures are making life ever more precarious. Nepal is currently ranked as one of the world's poorest countries (according to the World Development Report of 1985 only three other countries had a lower GNP per capita). Any improvement in the Nepa- lese economy has been largely off-set by population growth (2.66 percent and increasing). Despite investments in agricultural development, most of Nepal's rural population is undergoing a process of impoverishment resulting in increasing nutritional stress-with women and children most at risk.

\section{Women's Lives and Women's Work}

Throughout Nepal the vast majority of people are subsistence level farmers. The family farm produces almost 80 percent of the average annual household income. In the division of labor, the major workload falls upon the woman and it is simply assumed she will fulfill multiple roles. According to comparative time allocation studies, a Nepalese woman must spend almost 11 hours a day just to maintain the family's subsistence level. Men, by comparison, are involved in the family farm enterprise for approximately six hours daily.

According to the Status of Women Reports compiled by Tribhuban University in 1981, there is a general pattern of female predominance in agricultural decisions (and also household matters). Ninety-six percent of women described as "economically active" are engaged in agriculture as low levels of education continue to negatively 
affect employment of women in the formal sector. In addition to their contribution to the family farm and household maintenance, women also undertake "informal" economic activities such as small trade, marketing, various crafts and shop-keeping to supplement the household income. However, the time rural women in Nepal can spend on activities with potentially higher economic return is limited by their extremely heavy burden of providing food, water and fuel for the family and in caring for children.

As mothers, women play a critical role in their children's development, but they are often limited in their ability to nurture and stimulate their offspring because of social conditions that deprive them of access to food, services, resources and information. Equally important, they simply have very little time available to spend with their children. Each year it is necessary to go further up in the hills to collect fodder and fuel, taking more and more of their time.

In Nepal, almost 40 percent of children drop out of school during the first year. And of those who remain, 25 percent have to repeat grade one. This is indicative of the difficulty many children have in coping with the school environment. Access of girls and women to educational opportunities is particularly limited and today 82 percent of Nepalese women are illiterate. This has had a negative impact on their access to knowledge and their participation in the development process. Early on, girls are expected to participate in household labor, particularly in child care, thus reducing the likelihood that they will attend school. Combined with a general lack of confidence in the education system, this has meant that only 30 percent of school-age girls currently are enrolled at primary school; in some districts enrollment of girls is as low as 13 percent and, even when enrolled, their attendance is about 50 percent lower than boys.

\section{Child Care and Development}

The vast majority of births in Nepal take place in the family home assisted by a traditional birth attendant. The first few months of a child's life are often spent with the mother. Until children are six months old, they are often carried or kept in a basket. Infants usually receive a great deal of affection. Grandparents spend hours playing with them and they are constantly surrounded by other family members. They receive a lot of physical contact, which is important, as the quality of early social interaction is central to all children's development.

By the time a child is able to crawl, she/he is increasingly likely to be left in the care of other

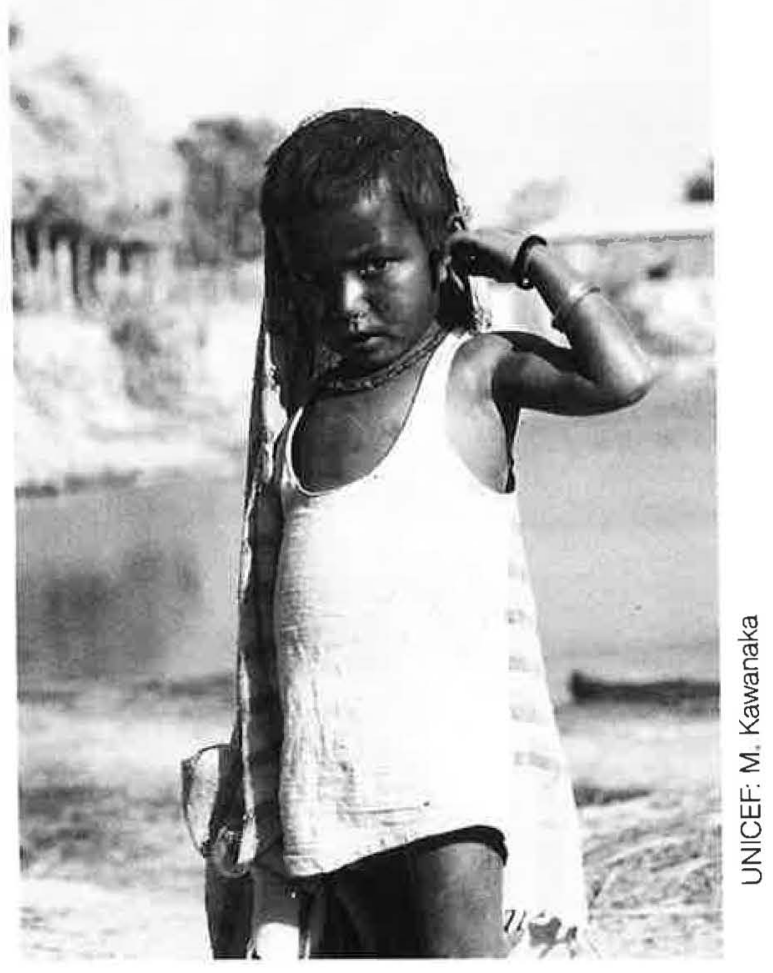

family members while the mother attends to farm work. As the young infant begins to explore, she/ he is exposed to a highly contaminated environment. Thus, from early on, the child's development is subject to frequent set-backs as disease undermines an already precarious nutritional status.

Many Nepalese children suffer from gross deprivation of their most basic needs and one out of six die before reaching their fifth birthday. Such high infant and child mortality rates (113 \& 165 respectively) not only underscore the vicious cycle of poverty, but also point to increased risks of damage for the survivors: According to the National Nutrition Survey's weight for-age data, two-thirds of Nepalese children under the age of six are malnourished and an additional five percent are very severely affected.

By the time children can walk, they are considered old enough to be left in the care of an older sibling. Girls of five, or even younger, are entrusted with the responsibility of looking after children of one or two. From this time on, the child's information concerning the world comes mostly from other children, rarely in the form of direct instruction but rather by means of imitation. Parents, however, are held responsible for the child's cleanliness, eating habits and moral qualities. 


\section{Identifying the Need}

In Nepal, child development programs must have a strong orientation towards health, nutrition, sanitation and parental education because the majority of children who do survive will, for the most part, continue to live in the same potentially debilitating conditions of poverty that put their lives at risk and now threaten their development. There is also an important place for a psychosocial component-often interwoven within other activities-as the developmental perspective compliments the emphasis on survival by addressing the question of how these children will live the rest of their lives.

Planning child development programs in Nepal must also take account of the increasing stress women are under just to meet the family's subsistence needs. The demands that accompany their dual roles as nurturer and worker can become overwhelming. The challenge, therefore, is to develop effective programs which simultaneously address both women and children's intersecting needs. Women's lack of access to education and information, as well as the pressures on their time, must be taken into account. Fathers, and the community as a whole, also need to be involved: Education and information should not be directed only at mothers.

In Nepal, expertise in the field of early child development is extremely limited as education below primary school falls outside the formal edu- cation system. The Nepal Children's Organization operates centers that provide pre-school education and day care for about 4,000 children, however, these centers are situated in district headquarters and serve the needs of government officials and town residents. While many private pre-schools can be found in Kathmandu, Nepal's capital, in rural areas there is an almost total lack of any sort of child care facilities.

\section{Taking Action}

The early childhood program described here has been developed as an integral part of the UNICEF-supported Production Credit for Rural Women (PCRW) project. Administered by the Women's Development Section (WDS) of the Ministry of Panchayat (the unit of local government in Nepal) and Local Development, the PCRW project provides support for a range of inter-linked credit and community development activities carried out by village women. Overall the PCRW project reflects UNICEF's basic services strategy: The child is set within the context of his or her community and the emphasis is on working towards social and environmental changes within the community that will benefit the community at large and thereby enhance children's overall health and development.

The PCRW project works through field staff to assist low-income rural women to take advantage of credit schemes available through national

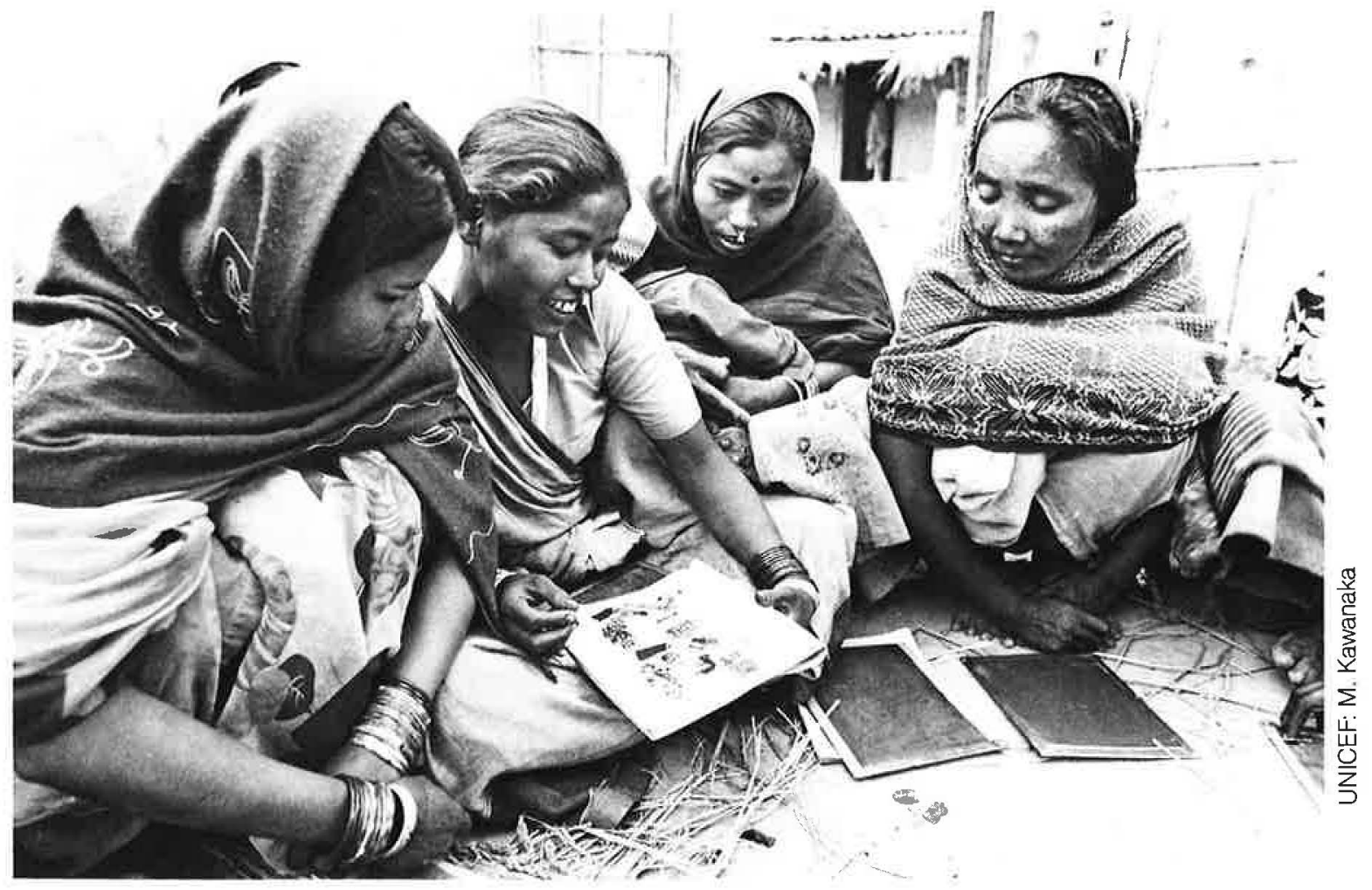


banking institutions for agricultural production, cottage industries and services. As these are the type of activities women are already doing, they are considered the most suitable income generation activities. The PCRW's community development component offers groups of women the opportunity to participate in the definition of local problems and the search for solutions. The activities undertaken vary from site to site according to perceived needs and available resources.

Besides having their own intrinsic merits, PCRW's economic and community development components strengthen each other because a woman's ability to take full advantage of economic opportunities often depends on the availability of services provided through community development efforts. And, as the focus of community development efforts has been on women's needs, the emphasis has been on projects that reduce the time it takes women to complete their daily chores-for example, providing water near the village, a mill for processing oil and grains or establishing child care facilities.

In the original project design, child care arrangements were envisaged as one small component of PCRW's community development approach, as the main concern was to free up women's time so they would be better able to engage in income generation activities. But more and more frequently field workers identified child care as a priority until it became a vital facet of PCRW's complex of inter-related activities.

Experience has shown that while child development efforts that are part of broader community development efforts are better able to benefit from multi-sectoral support and to garner cooperation from the community, the task of actually involving parents and establishing genuinely community-based participatory programs are long and complex. Further, the ability of communities, themselves often on the edge of the cash economy, to take over the running costs of the child care centers also has been problematic.

PRCW planners realized that in Nepal, center-based child care arrangements alone were not the answer. Working with UNICEF, they developed several low-cost strategies firmly based in the community and able to reach greater numbers of children.

- Home-based programs to be run by mathers themselves on a rotational basis for children up to three years of age.

- Community-based child care centers for children three to six years of age.

- Parent education classes, based at child care and community centers, covering subjects from pre-natal care to concerns of school age children.

- A Child-to-Child program that would strengthen older children's abilities to promote the health, welfare and development of younger children.

While all four strategies have been implemented to some degree, it is the home-based programs that have clearly been the most effective at meeting women's immediate needs for child care, providing a safe and nurturing environment for young children and offering local women a chance to learn new skills and develop selfconfidence.

\section{The Home-based "Entry Point" Program}

Referred to in Nepali as praveshdwar, which translates as the "entry point" or first door into a big, important place, this is by far the most innovative component of the Nepal project. Because of her central role in the family, the "entry point" program concentrates on the mother and begins in the village home.

Mothers who want to participate form themselves into a group (usually six). As with other PCRW activities, the group is the focal point for action. Before training is provided, the community must have arranged for a site for the program that includes a latrine and a kitchen. In some places, the community has given a room to the program; in others, particularly in the terai where cold is not a problem, they have constructed a small shelter. But in most instances, the mothers run the program on a rotational basis in their own homes (although often, if one of the mothers has a room that is not much used, she will offer this to the program) for children one to three years old. The members meet weekly to ensure the program is running smoothly and each group establishes a schedule according to its own needs.

A basic kit of materials, in a tin trunk, is supplied to each group. The kit contains cooking utensils, plates, cups, a bucket, a jug, personal hygiene materials, a rug, two dolls, three puppets, a ball and a drum. Besides the basic kit, a play material kit is also supplied, containing materials that help introduce specific concepts such as shapes, colors, body parts, domestic animals. Nine different kits are presently available, so neighboring groups periodically exchange kits, in this way exposing the children to a wide variety of toys and play materials. A range of bamboo toys, made by the fathers, are also used.

As almost all the mothers are illiterate, a pictorial chart is used to indicate the daily schedule of 


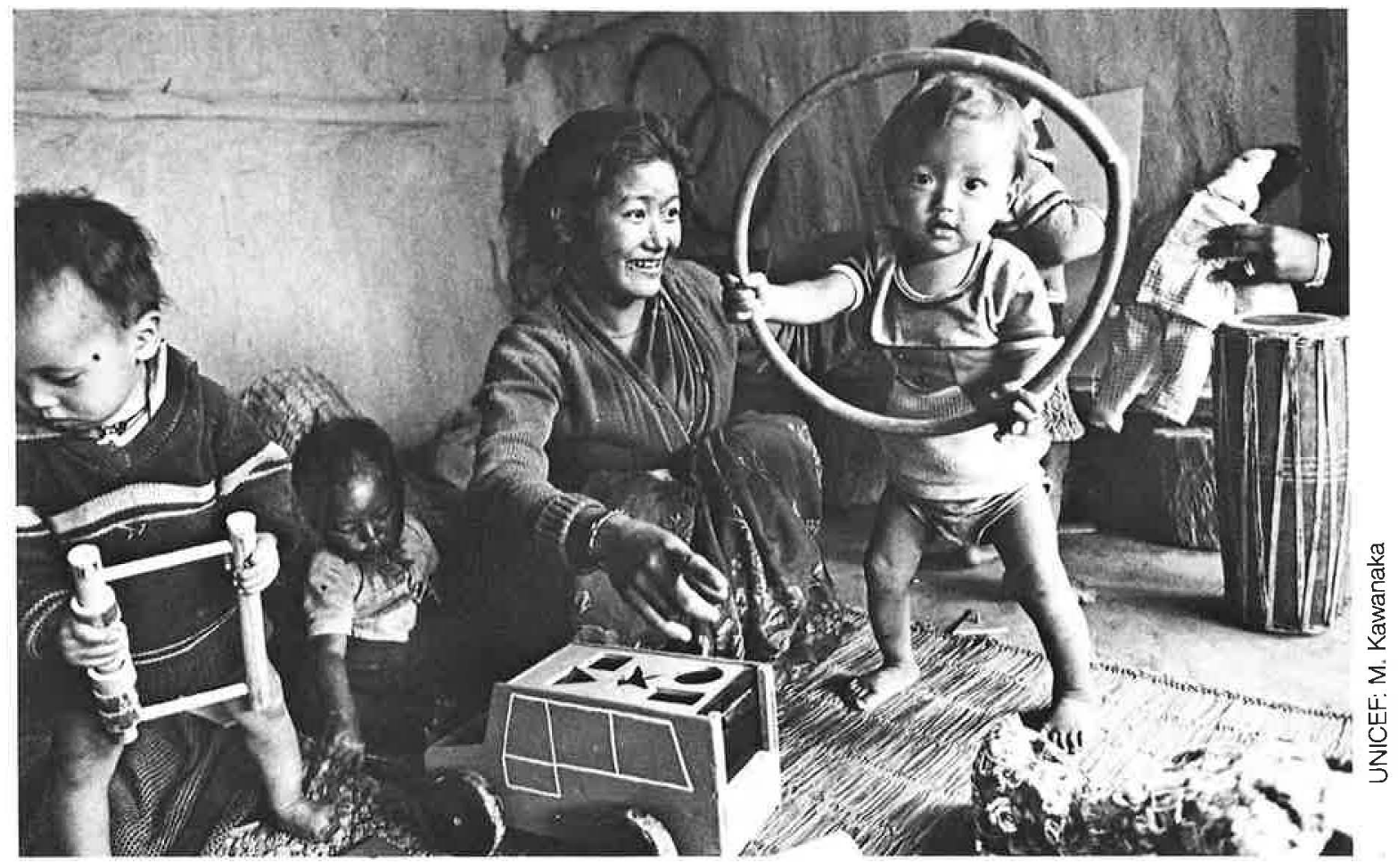

activities. Children engage in individual play activities that teach a variety of different skills and concepts and they play simple, creative, non-competitive games. A strong emphasis is placed on personal hygiene and use of the latrine. Each day the mothers contribute food to provide a nutritious meal.

Sri Maya is an "entry point" mother living in the middle hills of Nepal. This morning she is arranging a set of bamboo toys made by the village fathers as she waits for the children to arrive. Suddenly she hears laughing and chattering outside. The other children have started to arrive with their mothers and are wondering what game they will play today. Sri Maya gestures a formal namaste (the traditional greeting in Nepal) and then, one by one, takes each of the five children from their mother's arms and gives them a hug.

She discusses the weather for a moment with the women - they may be a little late coming to collect the children today. It looks as if the rains may be coming soon and the planting needs to be finished. This is no problem-one of the joys of running the group themselves is the flexibility it provides.

After helping the children get washed up, Sri Maya takes them outside where they play a new game in which they dance around while Sri Maya plays a madal (drum). When she stops they have to pick up as many corncobs as they can and place them in a big cane hoop. It takes them quite a while to get the idea and Sri Maya's four-year old son has to help the two-year olds.

One of the most notable things is the way Sri Maya is interacting constantly with either the whole group or an individual 'child. Even while preparing their lunch she is talking with themdiscussing the pegboard one has just completed, commiserating with the child who has a sick dolly, suggesting where someone else might look for the ball. And so the day progresses through games and stories and songs-Sri Maya always available to lead the exploration, join in the laughter and wipe away the occasional tear and spill.

Benefits from the "entry point" program, however, are not limited only to the children participating. The quality of interaction between mothers and all their children changes due to increased knowledge and confidence in their new role. Mothers also find that, although they are spending one day per week looking after a group of children, they actually have more time to engage in other activities, including income generation.

I used to think this program would interfere with my work but Naresh doesn't seem to get sick like he used to-I used to always be having to spend time at home because I was too concerned to leave him, he got so ill. Before, even when he was well, I used to worry about getting back to the house in the middle of the day to make sure everything was OK-and my fields are 
so far away it took me one and $1 / 2$ hours... And Sumita is so happy because she has been able to go to school instead of caring for him all day."

Moreover, by working co-operatively over an extended period of time, the mothers learn basic management skills and increase their sense of group responsibility. The skills and confidence they gain are then carried over into other community development and income-generation projects. And this is a two-way process: incomegeneration groups often end up starting a homebased child care program. As of May 1989, there were 54 groups in operation in 11 districts of Nepal and proposals had been received from 50 already established credit groups who were busy making preparations to start child care programs as soon as they could be scheduled for training.

\section{Training, Supervision and Evaluation}

Expertise in the field of early child development is, as previously mentioned, limited in Nepal. Therefore, at the beginning of 1986, UNICEF supported the establishment of Seto Gurans National Child Development Services. Seto Gurans has now assumed the lead role in meeting the training needs of the PCRW early child development program.

Training for the home-based program takes place on-site and lasts for four days. The training approach was originally developed in a small village through discussions and activities of WDS field staff and groups of village women. Since then it has continually been modified in response to field needs. Components include, in addition to general child development themes, a focus on health, habits of hygiene (especially important where 95 percent of the population do not have access to a latrine) and nutrition. In the nutrition component, mothers learn basic elements of both nutrition and growth monitoring. Nutritious meals are prepared using only locally grown food.

While the mothers attend their training course, the fathers are shown how to make the toys which will be used in the program. These toys are constructed out of bamboo, a material that is readily available throughout the country. The women are then trained in how to use these toys to play a variety of games that will be used to present different skills and concepts to the children. The training emphasizes the importance of the mothers' roles as "teachers," and aims to build up the women's confidence in their ability to manage and run the program. While practical arrangements are discussed during the training, the day-to-day decisions involved in running the program will be made by the women themselves.

Virtually all of the mothers in the "entry point" program are illiterate, so a good deal of time is spent on how to use the picture inventory in the basic kit and the daily schedule. In the beginning,

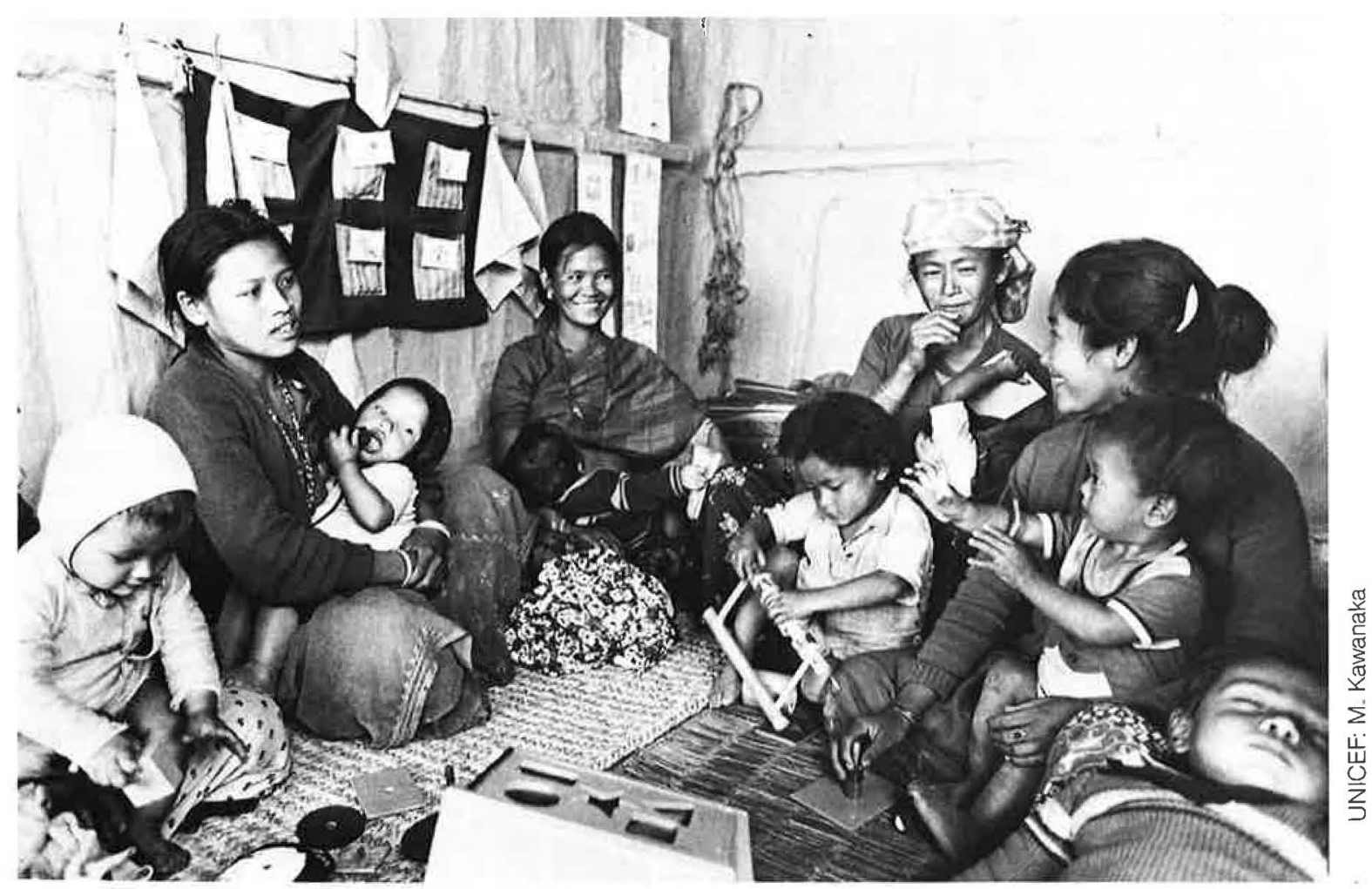


the mothers are often shy and reticent, but it never takes long before everyone is laughing and joining in the games.

Throughout the training, the mothers are involved in making up words to songs and deciding how they want to organize their daily schedule. They are surprised that their opinions are not only invited, but are being used. That it really is their program is very evident to anyone observing one of these training sessions. It is almost possible to feel the group grow in strength and dignity while, at the same time, they are falling over themselves laughing as they try out some of the games.

The early child care and development program in Nepal also includes child care centers serving groups of 25-35 children, three to six years old. Currently there are approximately 60 child care centers serving some 1800 children scattered through 32 of Nepal's 75 districts. Operated under the guidance of a community child care management committee, each center is run by two women selected from the community, a teacher and an assistant (known as a sevika). They are trained during a one-month course at Seto Gurans. While the women are supposed to leave their children at home, in reality there are always at least five or six infants who are still breastfeeding or children who are unwell and can't be left at home present during these sessions. In cases where a woman is living alone and has no one to look after her children, she will bring them along. In marked contrast to almost all other training programs in Nepal (even those that are supposedly serving the needs of women and children), Seto Gurans believes it is important that women who need to bring their children still be accommodated in the training program. This has always been done successfully, although it sometimes puts an extra burden on the training staff. Still they have no doubts that it is a correct policy decision.

Staff of the Women in Development Section, which administers the PCRW project, are divided into two major groups: 1) field staff (WDOs and WDAs) who facilitate the design and implementation of economic activities and community development projects, and 2) central staff who provide the technical, logistic and administrative support required for field work. Training for both central and field staff is an important part of capacity building. As with other PCRW activities, the group is the key. Before any training is provided a great deal of time is invested in the group formation process. The field workers (Women and Development Officers, or WDOs, and Women and Development Assistants, WDAs) have the vital role of initially mobilizing groups within villages. One of the great strengths of PCRW's field staff training is the attention given to respecting, building rapport with, and motivating village women. This has become the indispensable base for all PCRW village level training. Once a program is established, field staff continue to support, supervise and provide further training, factors that are, perhaps, the most important contributions in the long-term success of the program.

\section{Program Strengths}

The early childhood program has a number of notable strengths all of which are closely interlinked. These strengths pivot around the way program goals and activities have both evolved as family and community-based approaches and have been designed to meet the needs of working mothers. This is particularly true of the entry point program. Activities are not rigid, externally imposed prescripts, but rather exhibit a built-in flexibility that allows families and communities to take the lead role in deciding how they want things to run. The planning process starts with village women and is responsive to their perceived needs. Planning, management, supervision and support are all highly decentralized.

A second strength is that the multi-faceted child development efforts have been integrated within broader community development and economic activities. This too has had a positive impact on community participation. Moreover, the complex relationship between women's work, credit opportunities and early child care and development programs has been recognized.

Recognition of the crucial importance of the group process has been another strength. Forming groups around common purposes, such as obtaining credit or starting a home-based program, is critical to building women's confidence in their own abilities to improve their lives. The mutual support the women thereby provide to each other has many implications for improving their children's well-being as well. It is this principle of building on the strengths of women, families and communities, rather than using a "deficit model," which is so important.

This recognition of strengths is also central to the development of a training program that emphasizes respect for what people already know and do, and confidence building. In addition, training curriculum and program materials are all highly relevant, attractive, practical and well matched to the educational levels of the trainees. Recognition of the interactive effect between health, nutrition and stimulation is implicit in the design of the curriculum and this integrated approach is evident throughout all aspects of the 
early child care and development program.

Collaboration between a number of different agencies at different levels has contributed to the success of the early child education program. Collaboration between WDS and UNICEF, and Seto Gurans, has been important at all levels. UNICEF has provided both financial and practical assistance and has played an important role in supporting conceptualization and development of alternative, complimentary approaches.

Seto Gurans has provided vital technical assistance and support for development of training, materials development and supervision systems. At the district level, links with the government health services and with the community health component of PCRW have been emphasized.

\section{Problems Encountered}

In Nepal, dispersed populations, difficult terrain and lack of motorable roads place severe constraints on efforts to reach out to the children of Nepal and reinforces the need for strengthening the decentralized supervision system. Another major constraint is the continued dependency of the program on external funding. While the vital importance of achieving self-sufficient has been recognized for some time, progress has been slow. This is a lesson that should be kept in mind by other agencies embarking on similar efforts.

\section{Effects on Women, Children and Community}

Informal and anecdotal evidence suggests that the program is having a significant positive impact. The ability of early child care and education programs to free up mothers' time is an obvious and important benefit to women. The Chief of the Nutrition and Child Care section of WDS says that the comment, "We are mentally free now," is one she hears time and again when visiting the entry point groups and day care centers.

Within the home-based program, it is also clear that the mothers' active involvement in running the program has been just as important to their self-development as other PCRW activities. As their confidence increases in their new roles as "teachers," some begin to assume leadership roles in the community, and the management and organization skills they learn are useful in other activities.

One also sees the contrast between the children attending a home-based program or a child care center and children from a neighboring village where no early childhood activities are operating. This contrast is evident in terms of the children's general appearance, their health and nutritional status and, equally important, in their responsiveness, interactions and interest in exploring their surroundings. As one supervisor said, "There is a difference. The spark is strong.

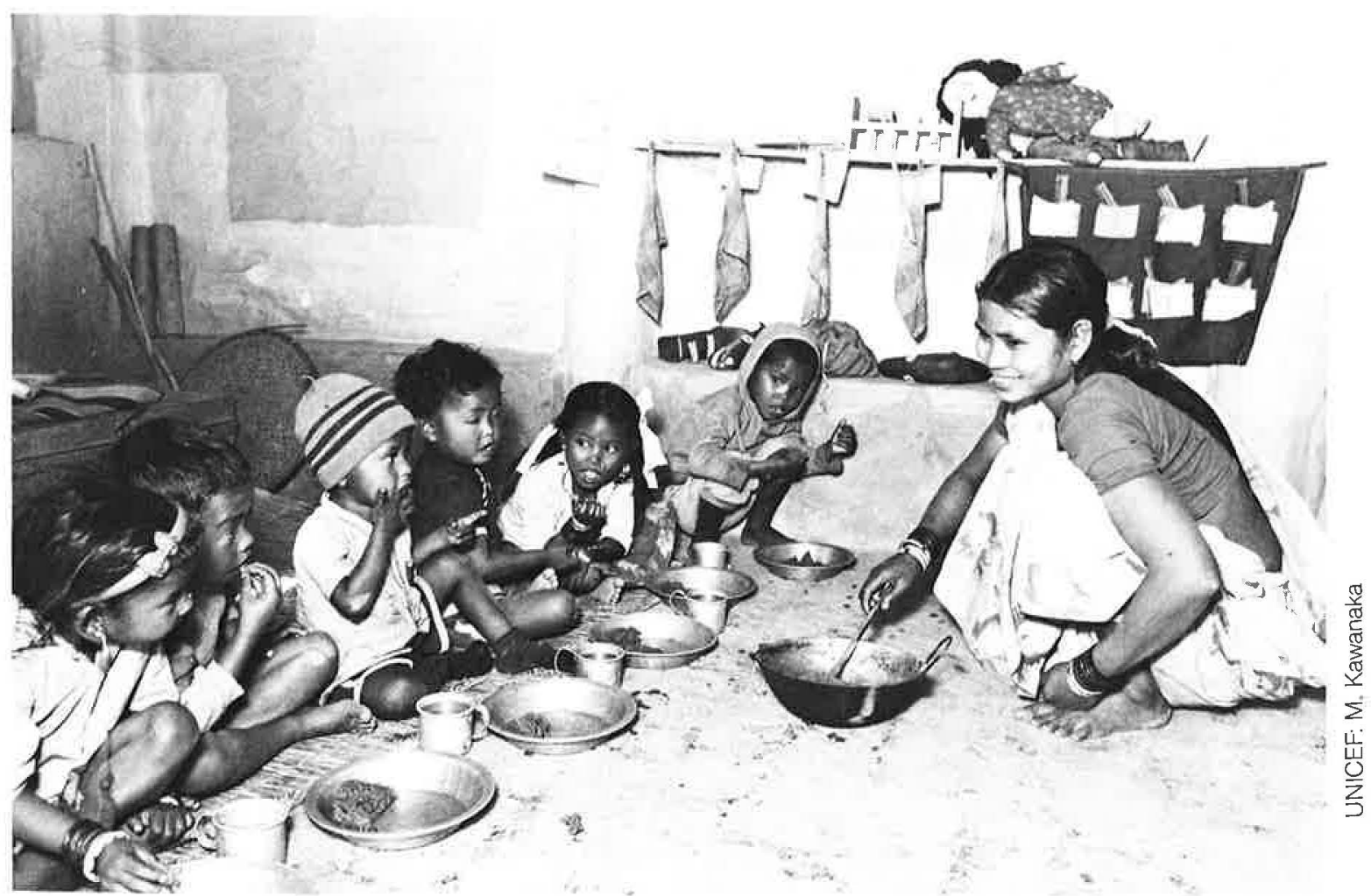


There is hope and happiness," or as a three-yearold in a home-based program put it, "It's fun. My mother knows how to play all these games."

The supervisor goes on to note that, "The impact of the program on children's health, nutrition and school performance is striking." Recent reports from WDOs in Kotari, Sivangunj and Tharpu districts report that all their child care center children are going on to the elementary school, and these are children from villages where previously less than a third of all children ever attended school. In addition, as Mikana K.C., one of the most experienced supervisors points out, "Children who have participated in an entry point program or a child care center don't drop out or have to repeat classes like the other children do."

"Childhood is the initial stage of life as the foundation is the first design of a house. The house can be strongly built only if the foundation is laid strongly. Similarly, if the child is to prosper and be strong, we must make the early childhood days good. Because life is so hard for almost everyone here, it is hard to think enough of children's health and better future, but our early childhood programs have created new avenues. Sometimes it is hard to provide even two meals a day, but we believe we can make our children's future brighter, as someone reaching their destination with a torch in the dark... I think we will reach our goal taking our own steps...."

Radha, a Mother from Utter Pari, Surkhet, Nepal

\section{Looking to the Future}

In looking towards expansion of the early child development program, attention needs to be given to issues of program replicability and sustainability. The integrated nature of the program, its "process" rather than "product" approach, makes replication more complicated than for projects focused solely on one problem.

Low cost programs facilitate expansion. However, whether or not low-cost programs can be developed that function effectively on a large scale is still an open question and careful cost analyses are needed. The idea that community participation does not cost anything must be abandoned. Where mothers and community members are the basic service deliverers, their training needs are considerable and training must be a continuing affair that is combined with intensive and capable supervision. The supervisors themselves also need good professional support.

For example, within the PCRW's early childhood education component, it costs approximately $\$ 120$ to get one home-based group

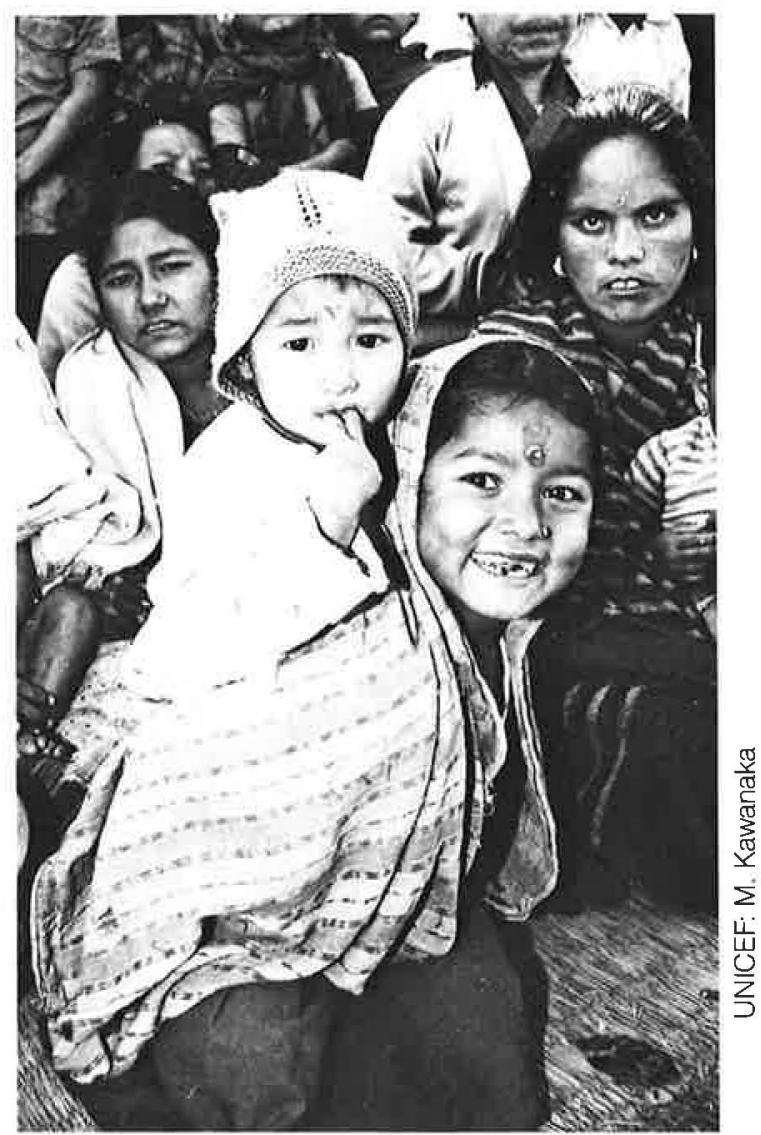

established, equipped and trained. After this, no external support is needed for the day-to-day operation of the program. While this is an impressively low figure, it must be remembered that the program is still small-scale and relatively new. The costs of follow-up training and support still need to be determined.

Income generation has been stressed as a primary means of achieving self-sufficiency and is a logical point of contact between PCRW's programming for women and for child development. Fruit tree growing and pig breeding are examples of activities that have been initiated in support of the child care center program in all sites. But while the child care centers may continue to be major focal points of the early childhood program, one of their most important functions eventually may be to serve as training and co-ordination resources for a variety of complementary early child care and education activities. 


\section{Ecuador: Community-Based Child Care Programs in the Suburbios of Guayaquil}

Located on the shores of the Guayas River, which flows into the Pacific Ocean, the city of Guayaquil is Ecuador's second largest city and most important port. During the last several decades Guayaquil has grown from 260,000 inhabitants in 1950 to 2,750,976 in 1989 (as estimated by the National Institute of Statistics and Censuses) as an oil boom, beginning in 1972, brought an expansion of modern industry and increased public expenditures in urban areas. Large-scale migration to Guayaquil has resulted in the growth of marginal slums and squatter settlements. Known locally as suburbios, these areas are characterized by extremely poor living conditions exacerbated by insufficient employment and income opportunities, substandard housing and inadequate access to social infrastructure.

\section{Identifying the Need}

In all the suburbios, women have been forced to make a more significant contribution to family income in recent years, working both at home and outside' as the cost of living has continued to rise. Nearly a third of working women perform income-earning activities at home, and 18.7 percent earn income outside their homes. Over half of this latter group work as domestic servants. More than 16 percent of all households in the suburbios are headed by women.

Children in the suburbios frequently suffer from poor health, as hygiene and sanitation in the outlying areas of Guayaquil are very inadequate and malnutrition is common. A study of local childcare practices, undertaken in 1988, found that when women with young children must go out to work, they often resort to locking their children up in the house while they are away, or older daughters end up minding younger children, thus missing school.

\section{Taking Action}

As existing child care facilities in the marginal areas of Guayaquil were few, and those available were beyond the means of most residents, UNICEF and the Government of Ecuador incorporated day care as an integral part of the Project of Basic Urban Services of Guayaquil, begun in 1979 to promote integrated development within the city's marginal areas. The project included four basic components: Preschool Child Care, Primary
Health Care, Social Communication and Recreation, and Women's Promotion and Organization. The Program of Preschool Child Care began in 1979. The Program of Women's Promotion and Organization finally got underway in 1983, under the joint aegis of two institutions: The National Office of Women and the National Institute of Children and Families (known as INNFA, from the Spanish acronym).

The four programs were geared toward improving living conditions for inhabitants of selected marginal urban sectors of Guayaquil through provision of services and efficient, lowcost opportunities that incorporate community participation into the design, implementation and evaluation phases of the projects. They are of particular interest because their aim is to address problems affecting residents of the marginal areas of the city through a variety of different but interrelated activities. For example, the need of women in the suburbios to earn income was addressed directly through the Women's Promotion and Organization Program, which focused on incomegenerating activities, and less directly through the Preschool Child Care Program, which not only provides a source of good quality, reliable child care that enables women to work, but also provides employment as care givers to two specific groups of women: home care mothers and high school and college age promoters. Likewise, the Primary Health Program provided services to children involved in the preschool program.

\section{Setting Up the Child Care Program}

Like the Nepal program, the Program of Integrated Care for Preschoolers in Guayaquil provides two models applicable to an urban setting: The Community Home, and the Community Center models. The Community Home for Children $(\mathrm{HCl})$ model provides care for children of working mothers in homes within the community. However, in this case it is in the home of a female neighbor who has been trained to work full-time as a child care provider. She is helped by an assistant also trained by the program. Generally 15 children, ranging in age from three months to six years, stay at the $\mathrm{HCls}$ between eight and nine hours a day, five days a week.

The Community Center for Children (CCl) model offers care for a maximum of 100 children 
at a site provided by the community (a community center, church or sports club). Children from three to six years of age attend these centers five days a week, from three to four hours a day, during either the morning or afternoon session. They are cared for by young people selected by the community and trained by the program, known as Community Promoters.

Both community promoters and care giving mothers are selected by the community. In the case of care giving mothers, they must have experience raising children, their house must be adequate to provide good quality care to additional children and they must know how to read and write. In the case of community promoters, they must be secondary school or university students and reside within the community. Their duties are considered half-time employment. Supervisors are university-level professionals with experience in child care programs. The basic selection criteria for families participating in the program is that they are low income, the mother is working or looking for work, the family has no other appropriate member who can take care of the children and the family promises to comply with program requirements.

\section{The Women's Promotion Program}

The Women's Promotion Program seeks to assist women to improve their lives through provision of information, consciousness raising, train- ing, expansion of productive roles and relief of domestic burdens. It encourages women to come together to solve problems and to design, execute and evaluate social programs.

In addition to organizing women within the community, the women's program has developed a Basic Staples Marketing Network made up of "honest" storekeepers, selected by the community, who promise to sell basic staples (such as rice, sugar, eggs, etc.) at fair prices in exchange for access to training and credit programs operated by INNFA. The women's program has also managed to establish, in cooperation with commercial banks, a loan program for micro-entrepreneurs as well as offering training in variety of areas, including non-traditional subjects for women such as auto mechanics and appliance repair. While the program gives priority to women, it does not necessarily exclude men. Women belonging to one of the program's neighborhood organizations may also be a care giving mother or promoter within the preschool program or may have worked as a community health promoter.

\section{How the Preschool Programs Operate}

Both the Community Homes and the Children's Centers are nonconventional and noninstitutional. They focus on the use of community resources - that is human resources (mothers, young people, leaders), physical.facilities (commu-

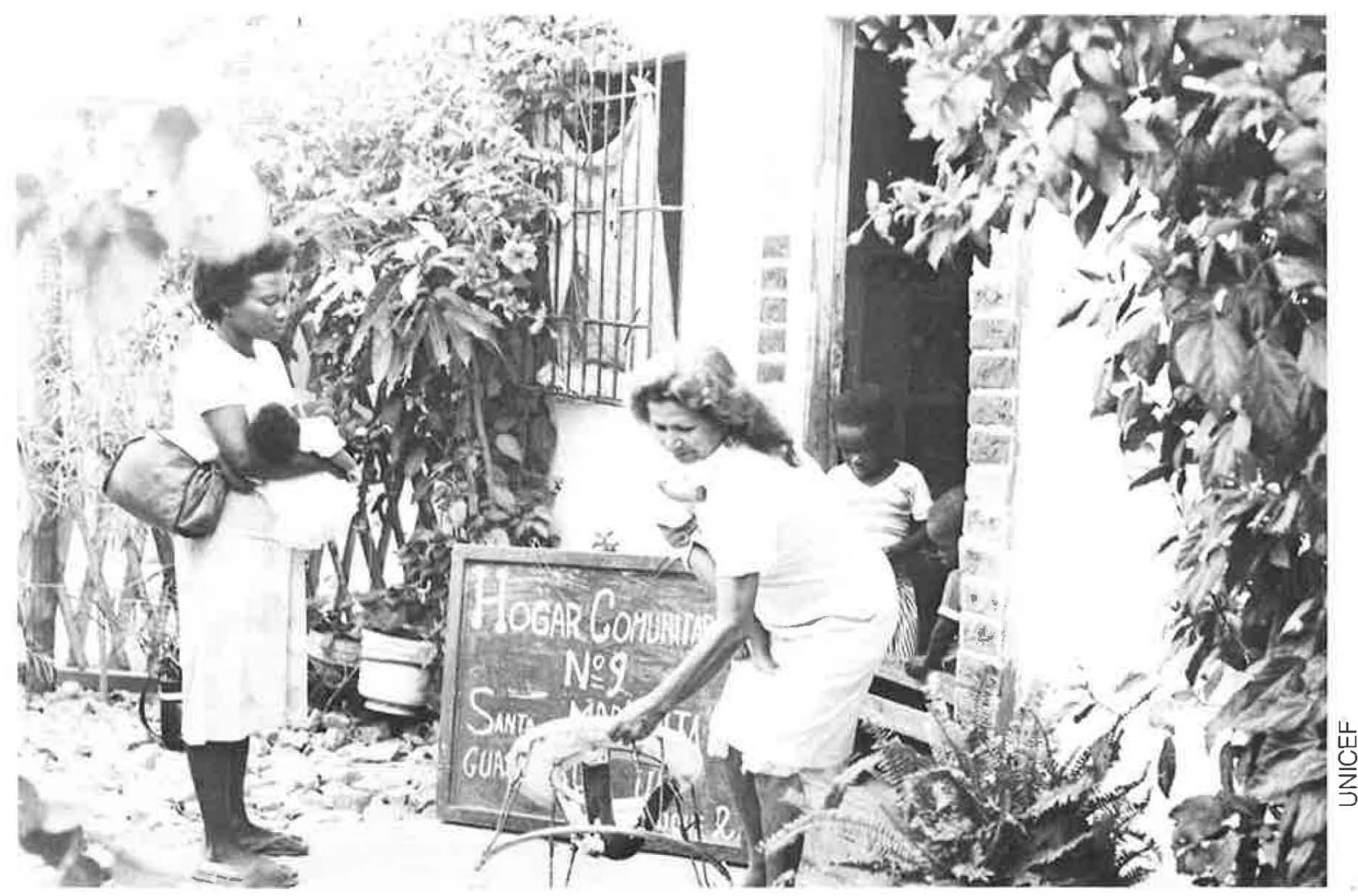


nity locales, buildings) and economic resources (contributions from the child's family) -that are mobilized to provide better care for children.

In the home care program, mothers bring their children to the designated neighboring home at 7:00 a.m., where they are greeted by the care giving mother. During the day the children participate in a variety of recreation and stimulation activities, such as painting, paper-cutting, pasting, singing, dancing, etc. They also are given three meals during the day.

\section{Doña Emperatriz}

Doña Emperatriz de Lara started working as a day care mother nine years ago and has been taking care of children in her home, uninterruptedly, ever since. Everyone who lives in the area knows her and her husband, a mild-mannered tailor, and their three student daughters. Her house, which is always open to visitors, is very clean and always being remodeled and enlarged. Although the maximum amount of children per household as defined by the program is 15 , she is always taking care of 17 or sometimes even 18, because her neighbors ask her to do so, and it is hard for her to turn them down. "This child came here three months ago skinny as a rail," says Doña Emperatriz, "and look at how plump and healthy he is now."

At the child care centers, children stay either from 8:00 a.m. to noon or from 2:00 to $6: 00$ in the afternoon. Most of this time is spent in stimulation and recreational activities. The children are given a snack midway through their stay. They are usually divided by age groups; each promotor assumes responsibility for no more than 25 children.

\section{Anita}

Anita started working as a promoter in a child care center seven years ago; she had just finished high school. She was particularly dynamic in working with children, never running out of energy. Little by little, Anita started helping her colleagues, showing them how to fill out the children's attendance cards, how to organize and lead meetings with the children's parents, and what exercises and songs the children liked most. So, after awhile, she was appointed as a supervisor and formally hired by the Ministry of Social Welfare to provide technical support to the other children's promoters. She probably is more widely accepted than other supervisors who do not come from the community; the children's parents know her well and feel confident about asking her advice.

\section{Education of Mothers, Family and Community}

An important activity carried out by the program, but one of the most difficult to accomplish, is educating the mothers who bring their children to the homes and centers for care. (Mothers and daughters are included in training events; fathers and brothers are invited but usually do not attend.) For one thing, there is the disparity in the mothers' educational level; second, many of them work downtown (especially as household servants) and put in long days which do not allow them very much time for meetings; the lack of available time is an even more serious problem for mothers who are the head of the household and carry enormous responsibilities on their shoulders. Therefore, parent education basically is achieved in two ways: during the daily interaction that occurs when mothers leave off and pick up their children and through meetings with the parents' committee in the Community Home every two weeks.

\section{Factors Contributing to the Success of the Program}

The Preschool Child Care Program effectively meets what the community feels is an urgent need. Working mothers view the Community Homes as a feasible and positive child care solution well adapted to their needs. Parents view the Community Centers as an opportunity for their children to develop, to make friends and above all to get ready for school.

The cost for these services to parents represents a small percentage of their income and is quite low in comparison with similar, privately-run services. However, the program does require that parents participate actively in the operation of these services by attending periodic meetings to discuss the economic problems, logistical aspects, food supply, etc. A very positive result of this greater involvement is that parents gradually acquire a greater awareness about the development of their own children.

\section{Problems Encountered}

While the program has been successful in mobilizing the community to support the integral care of children, a number of bureaucratic and political problems have been encountered. Government procedures for hiring personnel, for example, or for distributing funds to the communities are slow and complicated. And when a 


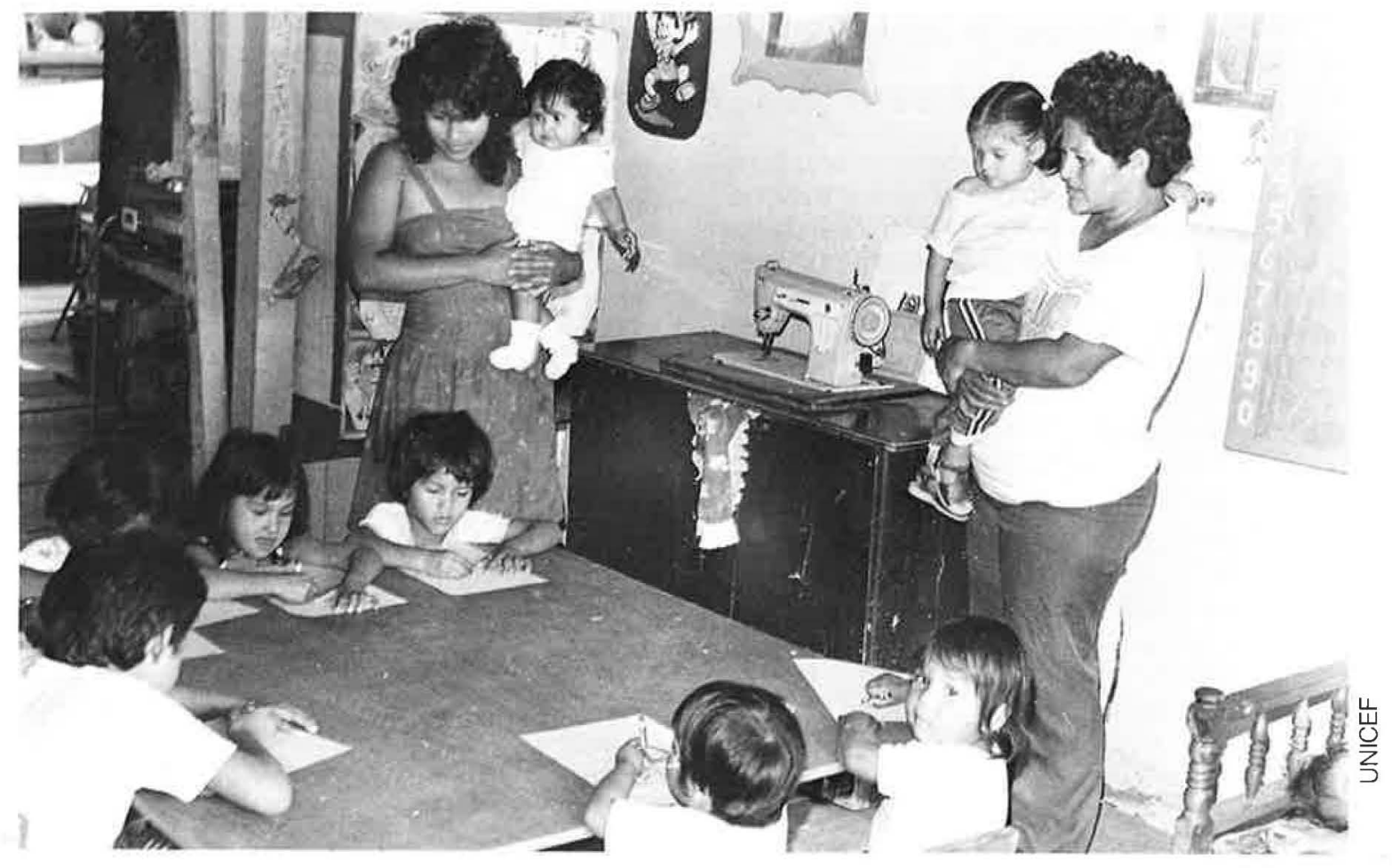

decision is made to transfer a certain amount of decision-making capacity and resources to community organizations, the necessary steps are not always taken to prepare the community, either in terms of training or in setting up control mechanisms.

On the local front, community leaders involved in hiring local promoters and day care mothers have frequently applied undue pressure on the Ministry to choose their relatives or friends, even though these individuals did not comply with established requirements, or have used their authority to pay local staff as an opportunity to exert influence or to demand payment of a small percentage of their wages as a fee. In addition, in the marginal urban sectors, especially in a city the size of Guayaquil, political activity is intense and the promoters and day care mothers are often subjected to political pressure.

\section{Effects on Women, Children and Community}

Since it began in 1979, the Preschool Child Care Program has been evaluated three times by outside teams, who emphasized the following results. First, both modes of preschool child care meet an evident need of the community. In the case of $\mathrm{HCls}$, for example, mothers can go out to work or look for work outside the home with the assurance that their children are being adequately cared for, fed and kept safe from physical risks. In the case of $\mathrm{CCls}$, children have the opportunity to develop their intellectual, emotional, physical and social potential. Such services did not exist in the community prior to the project. However, the demand for these services by the community is always greater than the program's capacity to respond.

The Preschool Child Care Program has had considerable impact on participating children's health and on their nutritional and psychosocial development. While updated information is not currently available, the testimony of care giving mothers indicates that many children who came to the homes poorly nourished have made quick recoveries. Obviously, care, regular feeding and prevention and control of diarrhea have all contributed to improving the children's nutritional status. The children from the homes and centers also have access to the Ministry of Health vaccination program.

While the most complex aspect, in terms of measuring the impact of the program on children, has to do with their psychosocial development, the children's improvement in the area of socialization is evident. They are less timid toward visitors and strangers and better able to share with their playmates. In the area of language development, the children are better able to express themselves. The environment of the homes and centers is definitely much more stimulating than their own homes, where preschool children's most frequent entertainment is watching television. (Most families in the suburbios do have televisions.) 
For working mothers, the greatest benefit of the child care program is the satisfaction and peace of mind that a mother feels when she leaves her child at a community home, where he or she will receive complete protection and care while she is at work. Something similar may be said of the parents whose children attend the CCls. Parents interviewed report that, since their children have been attending the $\mathrm{CCl}$, they are more alert and intelligent, less timid and are becoming prepared for school. However, since the centers provide care for children for only half a day, they cannot effectively meet the needs of most working mothers.

As for the child care providers, the two major advantages of participation for them have been the stipend that they receive (approximately U.S. $\$ 35$ per week in 1988 , or about 40 percent of the salary earned by a primary school teacher) and the opportunity to receive training in specific fields of social action. Another important incentive has been the opportunity to acquire higher status within the community.

\section{Program Costs}

An evaluation team (composed by the Ministry of Social Welfare, the National Development Council and UNICEF) that analyzed the Guayaquil Project estimated that by 1983 the cost of each $\mathrm{HCl}$, serving 15 children, included an initial investment of US \$210 and operating, supervision, technical support and monitoring costs, was US $\$ 1850$ per year. As for the CCls, the investment costs were estimated at US $\$ 876$, while operating, supervision, technical support and monitoring costs were estimated at US \$2620 per year.

Regarding financial support for the program, initially UNICEF's financial input made up some 80 percent of the total cost, with national institutions covering the remaining 20 percent. A mechanism was provided for increasing contributions from national institutions so that UNICEF's input might gradually decrease. In general terms, this mechanism has worked well but there have been difficult times, especially due to the slowness and inefficiency of public-sector funding mechanisms and the over-centralization of financial decision-making in the national capital. Despite these constraints, INNFA has now assumed full funding of the Women's Program and the Ministry of Social Welfare is carrying 90 percent of the cost of the Child Care Program.

\section{Looking to the Future}

Since 1979, when the first community homes were founded, the Ministry of Social Welfare has been able to expand the program practically nationwide. As of 1987, there were $69 \mathrm{HCls}$, $109 \mathrm{CCls}$, and 10 Home Centers (a new model), serving a total of 55,222 children and 38,653 participating families in Guayaquil. The national government which took office in August 1988, announced its intention to expand coverage to 108,000 children throughout the entire country, thus creating a so-called Community Child Care Network.

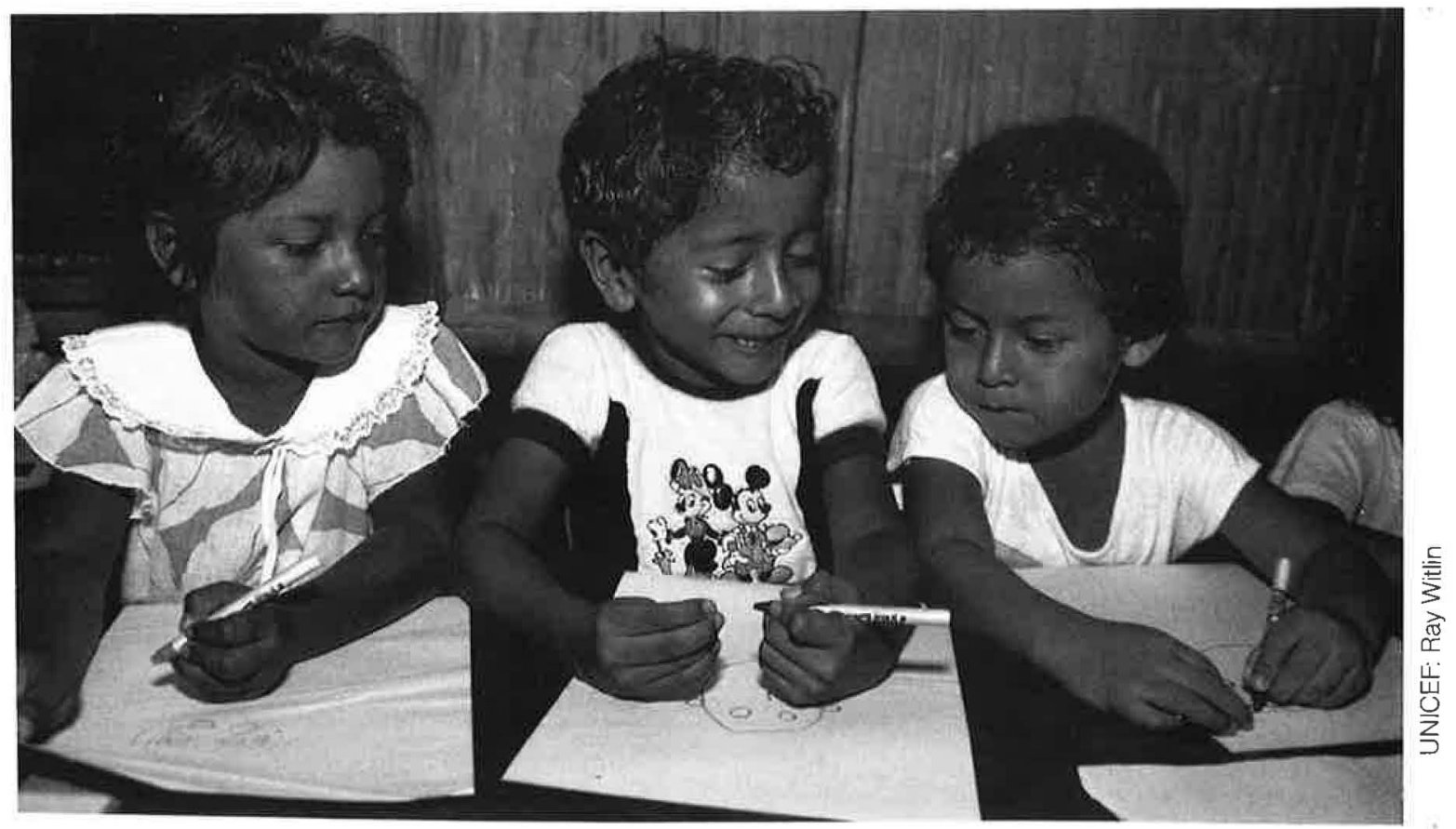




\section{Ethiopia: Providing Child Care within Farmers' Cooperatives}

The Melka Oba Farmers Producers' Cooperative is located about $120 \mathrm{~km}$. southeast of Addis Ababa, Ethiopia's capital. Accessible by road all year round, the cooperative is situated on a plain flanked by hills, dissected by the Awash River flowing from west to east. The area is hot and dry with very limited rainfall, making farming undependable for subsistence. Except for fruit trees and a few shrubs here and there, the land is completely deforested.

As part of Ethiopia's land reform program, 192 farmers and their families from the Harrarghe Region were resettled in Melka Oba by the government. Fruit growers by occupation, they were given 155 hectares of land that had formerly been owned by a private entrepreneur. The settlers103 men and 89 women farmers, 124 children $0-9$ years of age and 34 children between 10 and 15-organized themselves as a producers' cooperative and began growing fruits and vegetables for the local market.

Agricultural tasks on the cooperative are carried out in groups. Cooperative members are divided into six teams to carry out farming activities: two teams in the orchard, two teams in cereal production, one team in growing vegetables, two teams who serve as sentinels against thieves and wild animals. A cooperative organizer, a home economics agent and one development cadre from the Ministry of Agriculture's Woreda District office provide assistance to the cooperative. The average monthly income of a cooperative member is Birr 120 (approximately U.S. \$58). Payment is based on work points earned for seven hours of daily work, six days per week.

\section{Identifying the Need}

An assessment of the situation in Melka Oba prior to the start of the day care project revealed that the women were overworked in comparison to the men. Their tasks on the farm and in the house left them little time for relaxation. $\mathrm{No} \mathrm{MCH}$ services were available and children lacked proper care. The community did not have a clean and safe water supply and environmental sanitation left much to be desired. The result was that most of the children suffered from common health problems such as diarrhea, gastroenteritis, conjuctivities, malaria, and ear and respiratory infections. The infant mortality rate was reported to be very high.
In the cooperative, as mothers received only 45 days leave after delivery, they soon went back to work, primarily in the fields, for the entire day. This practice resulted in a dramatic decrease in breastfeeding. Also, when the mothers returned to work their children were often neglected, not having a conducive environment for sound physical, social and mental development. In the absence of mothers and fathers, young children were, in most cases, left to fend for themselves or elder sisters and brothers were charged with the responsibility of caring for their younger siblings, including infants. While an elementary school was situated about six kms. away from the farm, the absence of a day care center had forced the community to turn their 6-10 year old children into baby sitters instead of sending them to school.

Worse still, some parents would lock their houses when they went to the fields, so the children could not stay indoors. With the river so near to the houses, young children could easily drown; as wild animals and snakes roam about, the children were continually exposed to danger. The children also were not fed on time or properly. Overall, the absence of day care, inadequate clinic services, absence of pit latrines and refuse pits, lack of clean and potable water, all contributed to putting children and women in a hazardous situation. The community's attitude towards women was traditional, the men considering child care to be solely the women's responsibility, something they were expected to do in addition to carrying out time consuming and often arduous domestic chores and fulfilling their duties on the farm.

\section{Taking Action}

In 1982, the cooperative requested assistance from the district administrators to establish a day care center. It was willing to do everything within its means to realize this goal, provided it could receive the necessary technical and material support. The situation of women and children in Melka Oba was brought to the attention of the Integrated Family Life Education Project (IFLE), a semi-autonomous agency supervised by the Ministry of Labour and Social Affairs and mainly financed by UNICEF. It has been running integrated, non-formal and action-oriented family life education programs for many years.

In January 1983, IFLE established an Interagency Committee composed of the National 
Children's Commission, the Ministries of Health and Agriculture and UNICEF, with IFLE serving as secretariat. The purpose of the Inter-Agency Committee was to identify the needs of the Melka Oba Cooperative and to seek solutions that would improve living conditions there.

Establishment of a creche and a kindergarten were considered urgent interventions that would also serve as entry points for further initiatives in child survival and the promotion of social services. The goals of the project were to develop a program that would: 1) ensure the safety and proper care of children while mothers are away at work; 2) allow mothers time off for breastfeeding; 3) provide regular immunization services; 4) develop a program that would monitor the normal growth and development of children; 5) provide broad-based family life education programs to men and women of the community in areas of health, child care, nutrition, family planning, environmental sanitation (waste disposal, construction of latrines, etc.); 6) alleviate some of the burdens women face in providing water and fuel and in food processing, cooking, etc.; 7) ease farmers' burdens through provision of appropriate (basic) technology, such as wooden wheel barrows, to transport fruits to collection points; and 8) train traditional birth attendants.

\section{Implementation}

The strategy adopted was an inter-agency approach with responsibilities allocated between various organizations. IFLE took up the responsibility for coordinating and implementing the program with Birr 36,100 (U.S. \$17,388), provided by UNICEF.

The first phase of the project was to establish a comprehensive child development program that would eventually be managed by the cooperative itself. The cooperative set up, from among its members, a children's affairs committee that would eventually be responsible for the management of the creche and kindergarten. The funds provided by UNICEF were used to:

- employ a local consultant for eight months to train child minders and establish the day care center;

- cover the cost of training child minders, who would be members of the community selected by the cooperative members;

- purchase raw materials needed to make educational and play materials required during the training period;

- equip the creche and kindergarten with indoor and outdoor equipment;

- buy basic tools needed for production of play and educational materials by the child minders.

\section{Training, Organization and Management}

The cooperative provided a spacious villa to

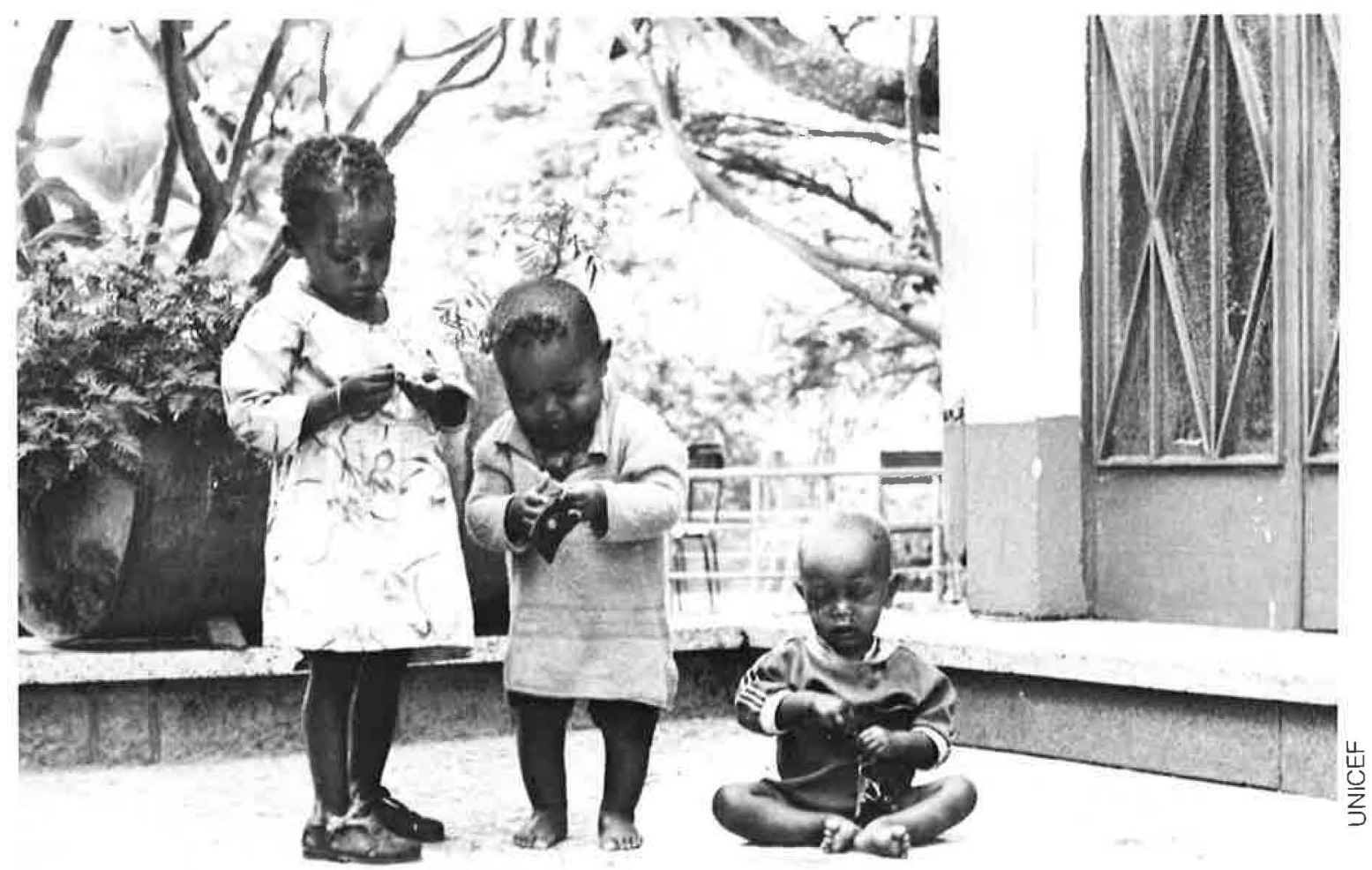


serve as the office for the executive committee of the cooperative and to house the creche and kindergarten. The National Children's Commission provided the necessary policies and guidelines related to child care and development. The Commission also helped to identify a trainer who would come to Melka Oba to work with the potential child minders.

Aster Wolde Giorgis, the child care trainer, is a woman in her mid-thirties. After being a preschool teacher for a number of years, because of her special skills in the production of play and educational materials, she became involved in a UNICEF-assisted pilot project to train preschool teachers. When the need for training semi-literate day care mothers in Melka Oba arose, Aster was selected as the lead trainer. Aster's ability to adapt to Ethiopia's different regions and cultural groups helped her to easily gain the confidence of the local community. Her training in modern psychology, child development, nutrition and health were helpful in encouraging the community to change some negative child care practices. At the same time, Aster was able to build positively upon local traditions by selecting appropriate children's stories and songs from the cooperative members' respective regions. Aster also was able to transfer her special skills in the production and maintenance of play and educational materials made from locally available materials using simple basic tools.

During the training, Aster lived with the trainees in the community. She organized day and night classes for the child minders and conducted discussions for cooperative members on topics such as nutrition, personal hygiene, home economics and day care management. Aster became a close friend as well as a teacher to the day care mothers and had the respect of the community.

In addition to her special skills in day care, Aster possesses a dedication to her work, a down-to-earth personality and the ability to adjust easily to local living conditions. She has played an important role in the promotion of day care in rural Ethiopia.

Child minders were selected from among the cooperative members on the basis of their interest in working with children and their educational level, which ranged from bare literacy to sixth grade. Training was conducted on site and lasted about eight months. The curriculum included creative work/materials production, child development, language development, number concepts, nutrition and hygiene, environmental studies, music, traditional dancing and art.
In all eight child minders (six female and two male) were trained. A young woman, 22 years of age, who had completed eighth grade and was trained at the National Institute for the Training of Day Care Teachers, was assigned to head the day care center. She manages the day-to-day affairs of the center and appears to be committed and enthusiastic about her responsibilities. The cooperative supports the day care center through a social fund set aside for social development.

\section{The Child Care Program}

Initially the day care center started with 100 children. Children aged 45 days and above are cared for in the creche. The kindergarten looks after children four to six. The center's hours are flexible, trying as much as possible to coordinate with the working hours of the mothers. Mothers with infants are now able to visit the creche several times each day to breastfeed their children, thus allowing breastfeeding to continue for a longer period that when children had to be left at home. A typical day at the center includes various indoor and outdoor activities. Daily lesson plans generally follow the national preschool curriculum, and the center provides immunization and health care services.

\section{Other Activities}

Prior to establishment of the day care center in 1983, there were no social services in Melka Oba. The existence of the day care program has had a profound effect on the cooperative, making members aware of the need for other services. The Ministry of Health has assigned a health assistant, who is assisted by a Community Health Attendant trained for six months in a nearby farmers' training center. The $\mathrm{MCH}$ unit of the Ministry of Health, the Family Guidance Association of Ethiopia and IFLE have provided training to members of the cooperative in family life education and family planning and a health program is now being carried out by the Melka Oba cooperative. IFLE still provides some support to the cooperative and occasionally supervises community activities.

\section{Effects on Women, Children and Community}

During the initial stage of project development, the Interagency Committee, particularly IFLE and UNICEF, agreed to have appraisal meetings on site and, as circumstances dictated, to have an evaluation of the program. In 1985, Dr. Andargatchew Tesfaye, Associate Professor at Addis Ababa University, visited the project site and interviewed staff of the implementing agency. 


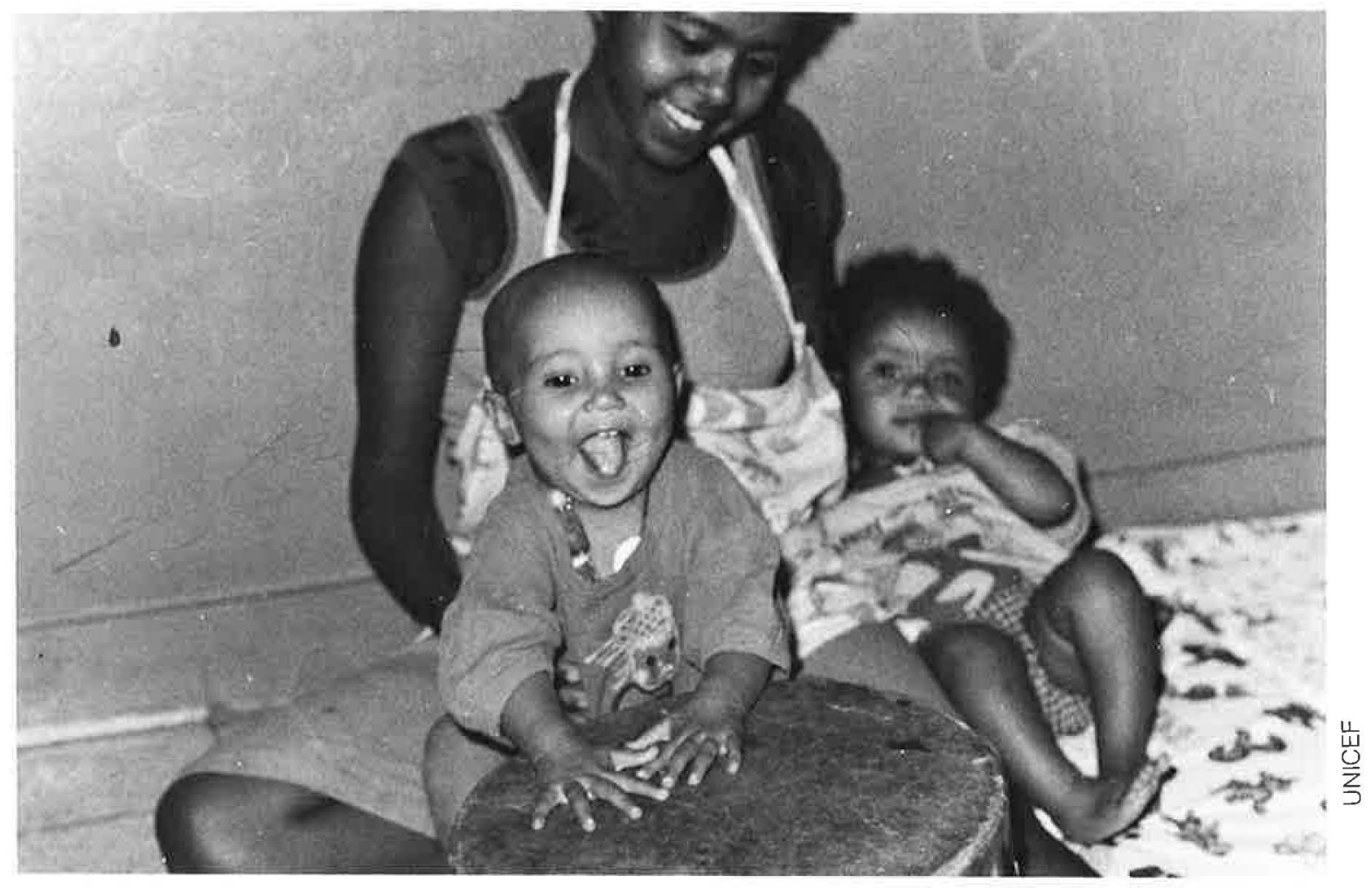

Highlighting past conditions and problems of child care, Dr. Andargatchew pointed out that the establishment of the creche and kindergarten at Melka Oba was a great relief to parents and, especially, to working mothers. All of those interviewed by Dr. Andargachew stated that they had witnessed noticeable changes in the health of their children since the program began; a view that was further corroborated by the Health Assistant and the Community Health Agent regularly serving Melka Oba.

Production too has increased because women are better able to concentrate on their tasks without worrying about their children. Absenteeism from work has fallen dramatically because of the reduced need to take sick children to health clinics. In addition to providing a relatively healthy environment and a balanced diet, the day care experience is meeting children's developmental needs and stimulating learning in all areas (physical, social, emotional and intellectual). This foundation provides for a smoother transition to and better performance in school.

In fact, a critical problem faced by the community was the placement of children from the preschool in regular primary school once they completed kindergarten. The nearest school was about six kms. away and young children could not walk that distance in extremely hot weather. Having received preschool training, parents were anxious that their children continue their educa- tion, so they put pressure on the Ministry of Education and an elementary school has now been established in Melka Oba. In addition, a functional literacy program for adults has also been started.

\section{Problems Encountered}

The first and most difficult job was to sensitize the community at large, and men in particular, that child care is not the sole responsibility of the mother, that parenting involves a partnership between both parents and with the community at large. Prior to the start of the project, when queried about the need for day care, the head man of Melka Oba told the IFLE representative that there was no problem with child care in the community -the women take care of it!

\section{Replicability}

IFLE and UNICEF built upon their experience as advocates of child development and survival initiatives to implement the integrated program in Melka Oba. In less than two years, IFLE assisted in establishing another child care program within the Yetnora Agricultural Producers' Cooperative located in Dejen District, Gojjam Region. 


\section{Lessons Learned}

1. Any attempt to adequately address the need for child care must take into account the needs of three groups: working mothers, infants and young children, and child care providers. The needs of these three groups are not contradictory. Rather, they are inextricably intertwined and only when they are addressed in tandem will the result be programs that positively address the developmental needs of children, enable women to be more effective earners (in terms of increased time available and reduced anxiety), and provide the means for women, and communities, to become more effectively involved in the welfare of their children.

2. To realistically meet the needs of working mothers, child care services must meet four criteria: a) they must be easily accessible, b) available during the hours women must be at work, c) offered at a cost that women can afford to pay and d) conducted in a manner that assures the woman that her child is being well cared for.

3. To provide high quality care for children, programs should exhibit the following characteristics: a) appropriate curriculum that includes childinitiated learning within a supportive environment; b) careful selection and training of staff and provision on an ongoing strategy for in-service training; c) keeping the staff/child ratio at an appropriate level; d) strong administrative support with linkages to comprehensive services such as health and nutrition; and e) effective monitoring and evaluation of children's progress. ${ }^{17}$

4. It is important to differentiate between the needs of mothers with very young and older children. For example, to the extent possible, care for infants should facilitate the ability of mothers to continue breastfeeding.

5. Home care and community-based programs are particularly effective in that they enable women to specialize: Most women become mothers but one group of mothers can take on the job of child care provider-sometimes on a rotating basis, as in Nepal. Training local women as day care providers not only offers them a source of employment, but increases women's sense of self esteem. It also offers an opportunity for them to develop a solidarity with other women that can be translated into social action for change. The potential power of women, once they come together in groups, can change their own and their children's lives.

6. Once trained providers need to be appropriately compensated and appreciated, not only in order to maintain quality care but to avoid high levels of turnover in personnel. They also require assistance from well trained field staff. As projects expand, they need to build up technical expertise and make skilled personnel available who can supervise, encourage and advise local women.

7. Programs that actively involve parents and the community in the planning and day-today operation of day care programs develop the community's capacity to meet its own children's needs, thus increasing the potential for sustainability when outside funding is phased out. Community provision of buildings, food, toys, etc., and the employment of local people as care givers, helps keep costs low; participation in the organization and operation of such programs increases self-confidence and the community's commitment to providing for the needs of its children.

8. Successful, community-based child care programs can serve as the gateway for the introduction of other development activities within the community, such as parent education, health care, sanitation, nutrition education, adult literacy, and income-generation. Quality child care/preschool programs also can greatly enhance the probability that children will be able to cope with, and thus remain in school once their formal education begins. Removing the need for older siblings to serve as child minders also enables more children (mostly girls) to remain in school longer.

9. Use of appropriate training methods and materials suitable to the educational level of the child care providers is a critical element in the successful implementation and operation of a community-based child care program. Teaching needs to be learner-centered, recognizing the strength of traditional child rearing practicies and respecting what women already know and have achieved. The focus should be on developing practical, common-sense, problem-solving skills and encouraging the growth of self confidence.

10. It must be recognized that there is no one solution to meeting the need for child care. Given the wide variation in women's work patterns, and the conditions under which women must work, no single model is going to be sufficient. Provision of child care on a large scale must be developed in such a way that flexibility to respond to the particular needs and circumstances of each community is maintained. The issue of "going to scale" must be approached carefully. Rather than attempting exact duplication of a successful "model" program (that may well be the result of a unique blend of people and circumstances), a more effective approach might be to establish mechanisms whereby local groups are able to share cornmon resources, such as access to training and supervision or cooperative purchasing of supplies. 
11. While community-based child care offers the best possibility of self-sustainability once outside funding is withdrawn, the need for continued follow-up and support of local child-care providers must be taken into consideration. On the other hand, the problem of excessive regulation that often accompanies significant expansion of programs must be avoided. Unrealistic standards, however well intentioned, can both drive up the cost and reduce the supply of child care services. In most settings, assuring the quality of care provided must be contextually judged and is generally best left in the hands of the mothers and the community.

12. Making quality child care available to meet the needs of working mothers cannot be accomplished without political commitment. Policy-makers must recognize the substantial economic contribution made by women and the indisputable link between women's ability to work and their need for child care. They need to understand the important role that early child care can play in preparing future generations to meet life's challenges and they must come to recognize the valuable contribution made by child care providers and seek to insure that they are adequately compensated for their work.

\section{Notes}

1. Facts for Life (UNICEF, WHO \& UNESCO). (Oxfordshire, U.K.: P\&LA, 1989.)

2. Dwyer, Daisy and Judith Bruce, eds., A Home Divided. (Stanford, CA: Stanford University Press, 1988.)
3. Leslie, Joanne and Mayra Buvinic, "Introducton," in Leslie and Paolisso, eds., Women, Work, and Child Welfare in the Third World. (Boulder, CO: Westfiew Press, Inc.)

4. Lloyd, Cnythia and Anastasia J. Brandon, "Women's Role in the Maintenance of Households; Poverty and Gender Inequality in Ghana. Paper presented at PPA, Washington, D.C, March 1991. (New York: The Population Council, 1991.)

5. Schmink, Marianne, "Women in the Urban Economy of Latin American," in Schmink, Bruce and Kohn, eds., Learning About Women and Urban Services in Latin America and the Caribbean. (New York: The Population Council, 1986.)

6. The Ford Foundation Letter, v. 21, n.2, Summer 1990.

7. The World Almanac and Book of Facts. (New York: 1989.)

8. Winikoff, Beverly, Michael Latham, Giorgio Soliamano, et al., The Infant Feeding Study. A report submitted by the Population Council to USAID in fulfilment of Contract No. AID-DSAN-C-0211, 1985.

9. Dwyer, Daisy and Judith Bruce, 1988.

10. Tolbert, Kathryn, "Availability and Need for Day-Care Services in Mexico City." Report to the Ford Foundation. (Mexico City: The Population Council, May 31, 1990.)

11. Tolbert, Kathryn, 1990.

12. Landers, Cassie. Innocenti Global Seminar Early Childhood Development: Summary Report. (New York: UNICEF, Consultative Group on Early Childhood Care and Development, October, 1989.)

13. Anderson, Janine and Nelson Panzio, "Transportation and Public Safety: Services that Make Service Use Pos. sible," in Schmink, Bruce and Kohn, eds., Learning About Women and Urban Services in Latin America and the Caribbean. (New York: The Population Council, 1986.)

14. Tolbert, Kathyrn, 1990.

15. Tolbert, Kathryn, 1990.

16. Mejia, Jorge, Memo to Cassie Landers, January 28, 1991.

Whitebook, M, C. House and D. Philips, Who Cares? Child Care Teachers and the Quality of Care in America. National Child Care Staffing Study. (Oakland, CA: Child Care Employees Project, 1989.)

17. Landers, Cassie, 1989

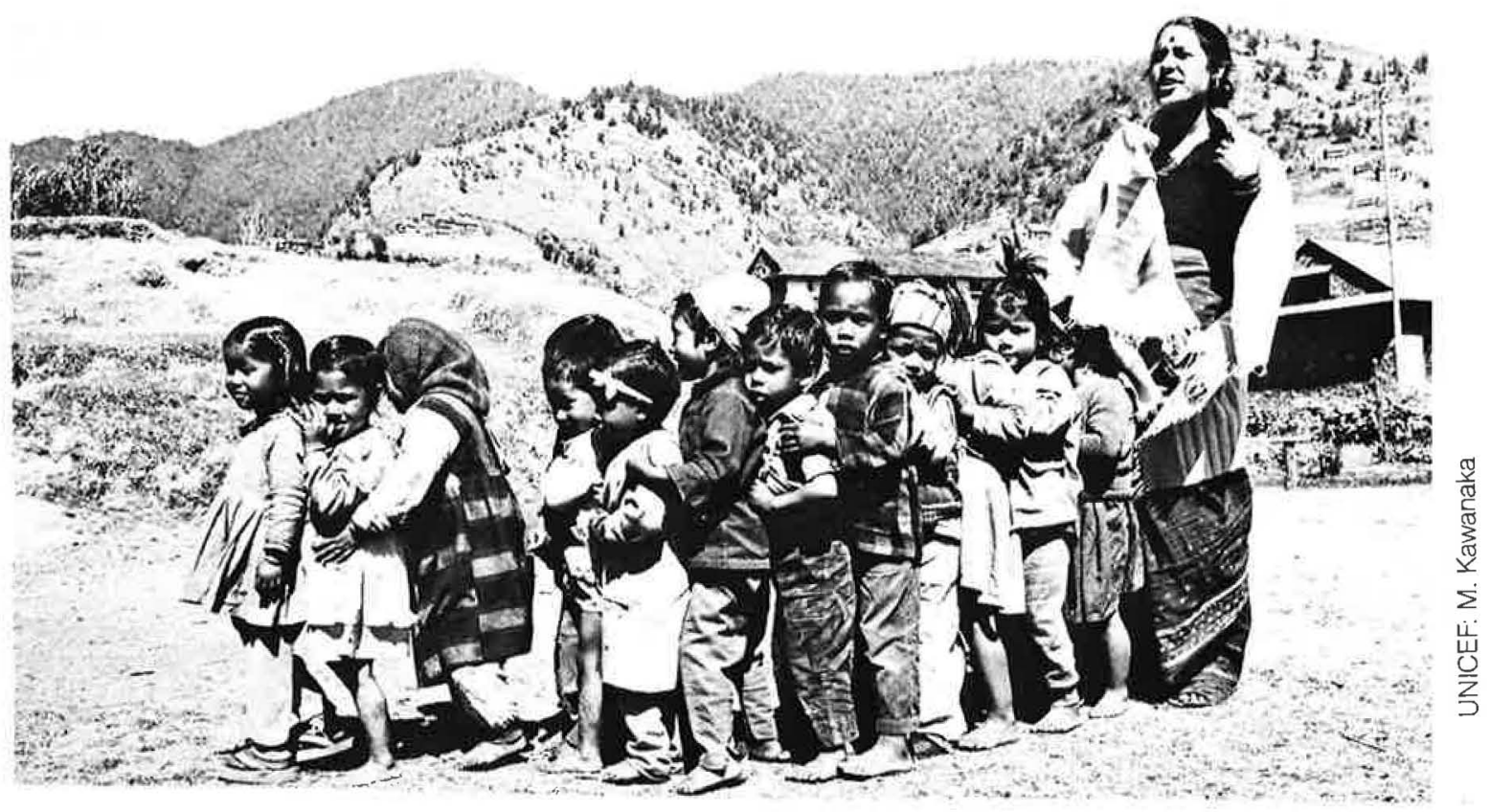


Design: Ann Leonard

Cover Photo: UNICEF: M. Kawanaka

Typography: Village Type \& Graphics

Printing: Graphic Impressions

A more complete version of the three case studies is available in the publication, Working Women and the Need for Child Care: Opportunities for Programmatic Collaboration, edited by Ann Leonard and Cassie Landers. Copies are available from the Consultative Group on Early Childhood Care and Development, UNICEF House, 3 United Nations Plaza, New York, New York 10017, U.S.A.

$\begin{array}{ll}\text { HQ } & \text { Arnold, Caroline. } \\ \text { 1870.9 } & \text { Child care } \\ . \text { S43 } & \\ \text { no.13 } & \end{array}$

POPULATION COUNCIL LIBRARY NEW YORK

We invite your comments and your ideas for projects which might be included in future editions of SEEDS. If you would like additional copies of this issue or would like to be included on the SEEDS mailing list, please write to:

$$
\begin{gathered}
\text { Ann Leonard, Editor } \\
\text { SEEDS } \\
\text { P.O. Box } 3923
\end{gathered}
$$




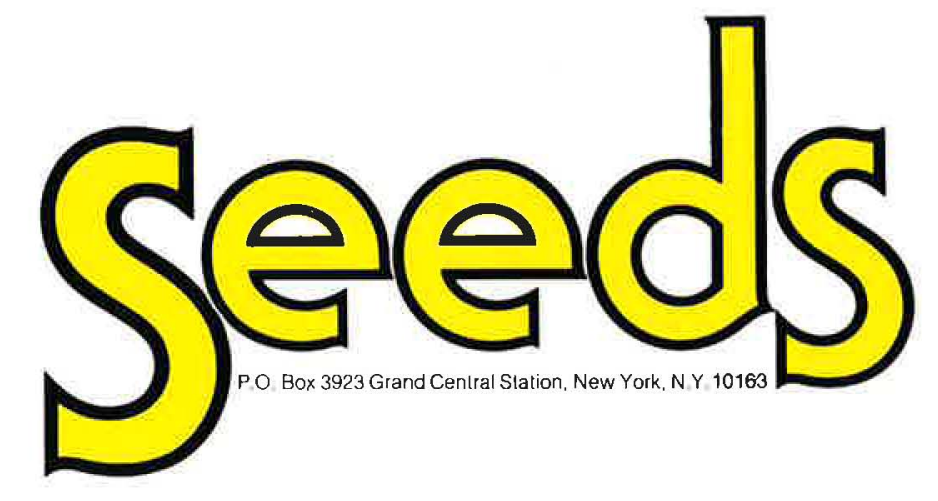

